\title{
Getting Bad News Out Early: Does it Really Help Stock Prices?
}

\author{
Chris Downing and Steve Sharpe*
}

October 2, 2003

\begin{abstract}
In this paper, we examine the stock price benefit of meeting or beating earnings expectations. Using a general methodology, we find no evidence that the timing of earnings news has any benefit for firms' stock returns. In fact, in many cases we find firms attempting to engineer positive earnings surprises by beating down expectations only to discover that their efforts are counterproductive. Our results appear to overturn the findings of previous authors who, using less general methodologies, have suggested that firms can boost their stock returns by getting bad news out early. Our results are robust across time periods, for different scaling factors on earnings revisions and surprises, when controlling for firm size and growth prospects, and when conditioned on past earnings news.
\end{abstract}

* We thank Eli Bartov, Mark Carey, Robert Hauswald, Andreas Lehnert, Michel Robe, and the participants at the 2003 Western Finance Association Meetings for helpful comments and suggestions, and Eric Richards for excellent research assistance. This paper represents the views of the authors and does not necessarily represent the views of the Federal Reserve System or members of its staff. Please address correspondence to (Downing): Federal Reserve Board, Mail Stop 89, Washington, DC 20551. Phone: (202) 452-2378. Fax: (202) 728-5887. E-Mail: cdowning@frb.gov. (Sharpe): Federal Reserve Board, Mail Stop 89, Washington, DC 20551. Phone: (202) 452-2875. Fax: (202) 728-5887. E-Mail: ssharpe@frb.gov. 


\section{Introduction}

Over the last decade, corporate chieftains seem to have become increasingly preoccupied with their quarterly financial results and whether those results meet their equity analysts' forecasts. Indeed, both market observers and academic studies have pointed out an apparent tendency for corporate managers to guide analysts' overly optimistic earnings forecasts downward in advance of the official release, so that the firms are able to meet or beat Wall Street expectations on the release date.

It is easy to understand management's obsession with meeting Wall Street estimates in light of the punishment frequently meted out to the stocks of companies whose quarterly results fall short of forecasts. What is more difficult to understand is how firms could benefit from managing down current quarterly forecasts by "preannouncing" bad news several days or weeks before their final results are released. If, at the end of the day, the total news is the same, then any benefit to the stock price at the earnings announcement should be entirely offset by the earlier negative price impact at the time of the warning, rendering the cumulative return insensitive to the timing of the news. This standard efficient markets view, however, seems at odds with popular perceptions. Moreover, some recent academic studies also conclude that managing expectations down ahead of bad news reduces the total stock price impact of the news.

In principle, testing the hypothesis that firms can boost their near-term stock prices by managing expectations should be straightforward. Controlling for the total earnings information revealed over the period in question - the gap between realized earnings and the beginning-of-quarter forecast (the "total forecast error") — one can test whether the timing of information revelation matters for the cumulative stock return over that period. While a number of recent studies have attempted to implement this testing strategy, the results are somewhat contradictory and the methodologies may not be robust.

In this paper, we examine the stock price benefit of meeting or beating expectations using a general, yet intuitive, approach. Our methodology most closely parallels Kasznik 
and McNichols (2002) and Bartov, Givoly and Hayn (2002), both of whom measure interim earnings news using revisions to analyst forecasts. Kasznik and McNichols (2002) gauge the rewards to meeting analysts' annual earnings forecasts by testing whether meeting (or beating) those forecasts has a positive incremental effect on stock price, while controlling for the total information revealed over the year. Indeed, they find a positive incremental effect of meeting the expectations at the time of the earnings announcement. Bartov et al. (2002) conduct a similar experiment, but focus on quarterly earnings. They also find that meeting expectations has a beneficial stock price effect, even after controlling for the total earnings news over the quarter, including the day of the report.

A clear implication of these findings is that earnings news released during the firm's performance period, that is, during the year or quarter, has a smaller stock price impact than the same news released around the time of the actual report. This suggests that firms can boost their stock prices by releasing negative news early, when price responses are lower, while keeping any good news under wraps until the earnings report, when price responses are larger.

Like these and a few other studies that have appeared recently in the literature, in this paper we estimate the effect of quarterly earnings news on quarterly abnormal stock returns by splitting quarterly total forecast errors into two contiguous pieces: (i) a forecast revision, defined as the difference between analysts' forecasts early in the quarter and their forecasts three days before the earnings announcement; and (ii) an earnings surprise, defined as the difference between the three day forecast and actual reported earnings. We then estimate the effects of these forecast revisions and earnings surprises on the cumulative abnormal return over the period.

The most important methodological difference here is our use of nonparametric estimation, which allows for a wide range of abnormal return response functions. Given the potential nonlinearities that might underpin the relation between earnings news and stock returns, we argue that careful consideration should be given to the form of the assumed 
response function. Most of the previous studies have assumed that the response of stock returns to earnings information is linear, with the possible exception of a discontinuity at an earnings surprise of zero. Indeed, under any number of possible nonlinearities, such regressions would be prone to incorrectly accept the hypothesis of a discontinuity at zero.

To estimate the abnormal return function, we employ the locally weighted least squares (loess) method (Cleveland (1979), Cleveland and Devlin (1988)), which allows for a wide range of possible functional forms. Moreover, under standard assumptions on the error term, the statistical properties of the locally weighted least squares estimator are well approximated by those of the the ordinary least squares estimator. The principal drawback to loess is that it is a computationally and data intensive procedure, but given recent advances in computer speed and our very large dataset, these drawbacks are significantly mitigated in our application. We report our results in the form of three-dimensional plots of the abnormal return on the vertical axis against the forecast revision and the surprise on the horizontal axes, thereby allowing one to examine the estimated tradeoff that firms face at a variety of points in revision-surprise space.

A second important methodological difference between our study and previous work is that we focus on the econometrician's choice of the "preannouncement period," and suggest that revisions early in the quarter might reflect the previous quarter's news. If analysts do not fully incorporate the previous quarter's earnings announcement into their newly updated or reconfirmed forecasts, but the stock price does immediately incorporate the information, then revisions to these early-quarter forecasts might not convey as much information to the market as revisions that follow company guidance later in the quarter. This would create a spurious asymmetry in the magnitude of stock price responses to forecast revisions and earnings surprises.

Finally, we examine the choice of the scaling factor applied to the forecast revisions and surprises - a choice that we argue could influence the results. It is conventional in accounting studies to normalize by beginning-of-period stock price, which reduces problems 
with outliers. We argue that, in theory, expected earnings (or book value) is a preferable measure. We find that the expected earnings scaling factor produces fits that are slightly superior, in a statistical sense, to the fits produced by the price scaling factor.

In contrast to previous studies, we do not find any short-term stock price benefit to preannouncing bad news. In other words, we find little or no difference in the sensitivity of stock returns to early forecast revisions and earnings surprises. This conclusion appears to be robust across practically the entire range of the data. In particular, in most cases we do not even see a benefit from nudging analysts' forecasts so that the earnings surprise is zero or slightly positive rather than slightly negative. Finally, we look at whether these results obtain when we condition on the size of the firm and on the firm's growth prospects as measured by analysts' long-term growth forecasts. While we do find that the stock prices of high-growth firms, particularly small, high-growth firms, tend to be much more sensitive to quarterly earnings news than those of low-growth firms, we again do not find any significant asymmetries in their sensitivity to news released early versus news released at the earnings report.

This paper is organized as follows. In the next section, we provide an overview of this rapidly expanding literature. Section 3 describes the data in detail and discusses our empirical methodology, and section 4 lays out our results. The final section concludes.

\section{Previous Literature}

Over the past decade, the consensus-meeting game played by corporate management and equity analysts seems to have become a dominant feature of the corporate reporting landscape. In general, firms can meet over-optimistic expectations in one of two ways. They can "manage" their financials in such a way as to boost the earnings they actually report, or they can provide guidance to analysts well before earnings are actually reported, causing analysts to immediately mark down their forecasts. Our analysis focuses on the latter behavior. 
Early evidence on the asymmetric nature of management disclosures is provided by Skinner (1994), who found that, more than a decade ago, 67 percent of early quarterly disclosures conveyed bad news. Kasznik and Lev (1995) show that this asymmetry did not merely reflect the state of forecasts relative to the economy, but a greater propensity by management to divulge significant earnings news early when that news was negative. Moreover, the propensity to avoid the negative announcement-day surprises appears to have become increasingly pervasive over the last decade. For instance, Matsumoto (2002) shows that in a large and growing percentage of cases where quarterly reports matched or even beat expectations, those reports were negative surprises relative to where analyst forecasts stood one to two months prior to the report (see also Burgstahler and Eames (2002)).

Media reports often presume that preannouncements are aimed at softening the impact of bad news on stock prices, but the underlying motivation remains a subject of growing debate in the academic literature. Skinner (1994) and other early research on the topic emphasizes that the threat of litigation gives rise to an asymmetry in the penalty for reporting significant downside surprises. A number of authors have offered behavioral rationales, such as the presumption that analysts are more embarrassed when a company that they follow reports a negative surprise than when results top their forecasts. A third type of rationale invokes signaling: By preannouncing bad news, firms might signal that they have some understanding of the situation. In particular, Liu and Yao (2003) argue that firms preannounce bad news to signal they have better growth prospects than firms that don't preannounce bad news. This last rationale, if not the others, would seem to suggest that the consensus-meeting game is designed to boost (or perhaps just bolster) the firm's stock price.

Some recent studies propose more insidious motivations. For example, Aboody and Kasznik (2000) offer evidence that managers are motivated to make bad news public or hold back good news prior to receiving installments on executive stock option grants. By moving forward and perhaps exaggerating its negative stock price impact, preannouncing bad news lowers the strike price on newly-granted stock options, thereby raising the potential value 
of the options to managers. In contrast to previous explanations, this rationale does not imply that prereleasing negative information benefits the firm's stock price in the short- or long-run; rather, it merely pulls forward in time any downward price adjustments.

In a similar vein, Richardson, Teoh and Wysocki (2003) point out that the window during which insiders can sell shares, and when firms tend to issue shares, usually follows official earnings releases. If management believes that the market temporarily overreacts to bad news, or that the market reacts less to bad news when it is disseminated prior to the earnings report, then preannouncing such news well before both the report date and the window for selling shares could bolster the price that managers receive on sales of shares to the public. A similar argument, which may be more easily reconciled with market efficiency, is that preannouncing bad news might simply reduce the variance of the price received on post-report share sales, by providing more time for the information to be digested.

While there is little agreement on the primary motivation behind the consensus-beating game, there does appear to be mounting evidence that playing this game has a positive impact on stock prices. Such evidence has taken one of two forms. One approach to gauging that impact is by analyzing valuations (the level of stock prices) to infer whether firms that tend to meet consensus forecasts on the report date also tend to be more highly valued (Chevis, Das and Sivaramakrishnan (2002), Liu and Yao (2003)). This type of evidence, though highly suggestive, must be viewed with at least some skepticism, as it is difficult to control for firm characteristics and insure that the true direction of causation is not the reverse. In particular, it is difficult to control for the likelihood that highly-valued "growth firms" are more prone to play the consensus-beating game. Indeed, those firms should be more motivated to do so if, as suggested by Skinner and Sloan (1999), they are penalized disproportionately when their reported earnings do fall short of consensus forecasts.

The most direct evidence on the stock price benefits of playing the consensus-beating game comes from studies that analyze stock returns. One of the first studies to try gauging the effect of company preannouncements on stock prices was Kasznik and Lev (1995), who 
identify discretionary management disclosures via a NEXIS News search. They analyze fourth-quarter earnings announcements from 1988-1990, focusing only on observations with substantial total forecast errors between actual earnings and forecasts 30 days after the previous quarter's earnings announcement. Controlling for the total forecast error, they find no evidence that issuing an early disclosure boosts cumulative returns. In fact, among firms with substantial negative forecast errors, they find that issuing an early disclosure has a negative effect on the cumulative returns measured over a narrower window.

More recently, Soffer, Thiagarajan and Walther (2000) analyze the stock returns of companies identified by First Call as having issued quantitative preannouncements no earlier than two weeks prior to quarter-end. They find that, even after controlling for the total forecast error (the difference between actual earnings and the forecast at the time of the preannouncement), having a negative earnings surprise on the earnings announcement has a negative effect on total-period stock returns. Moreover, they find that stock prices are more sensitive to the amount of negative news when it is released at the earnings announcement, suggesting that firms can reduce the impact of negative news by preannouncing it.

These ideas are further tested in the study by Bartov et al. (2002), henceforth BGH, who analyze roughly three-month cumulative returns for all firms whose quarterly earnings are forecasted by analysts tracked by Thompson/First Call. Again, controlling for the size of the total forecast error, they test whether cumulative stock returns are affected by the timing of earnings news. Their methodology is similar in spirit to the analysis of annual earnings surprises by Kasznik and McNichols (2002). In both studies, news is gauged solely by changes in analyst estimates, and in both cases, it is found that the cumulative returns on stocks of firms with bad news (negative forecast errors) are higher when the bad news is reflected in forecasts before the earnings announcement. The implication is that firms can dampen the effects of bad news by driving down analyst forecasts prior to the earnings report, through preannouncements or quieter means. ${ }^{1}$

\footnotetext{
${ }^{1}$ Firms' scope for influencing analysts' forecasts by quieter means was significantly limited following October 23, 2000, when the Securities and Exchange Commission adopted Regulation FD (Fair Disclosure)
} 
BGH recognize the potential for nonlinearities and provide relatively compelling evidence using difference-in-means tests. In particular, they divide observations into buckets according to the size of the total forecast error. Among the set of observations falling within any given range of total forecast errors (e.g., -5 to 0 percent), they compare the average abnormal return for observations where there is a negative surprise on the report date to the average return among those where there is a positive surprise. Our approach differs from BGH in two potentially important respects. First, our methodology uses a continuous distance metric for defining which observations are "close" to one another in the sample space. Second, among observations within a given neighborhood, our estimation strategy allows for a slope, as well as an intercept, in estimating the abnormal return function. While this should make our estimates less biased, the potential downside is a loss of precision.

Venkatachalam and Wang (2000) recognize a need to allow for nonlinearities, but they estimate an earnings response function that only allows for some select breaks in the linearity assumption, including asymmetries in the response to positive and negative information. Their results partially confirm those of BGH, but suggest a more complicated story in which the benefits of lowering expectations are not uniform. Still, these inferences may be just as sensitive to their parametric restrictions, which presume linearity over large ranges of the data.

Our approach to the question essentially amounts to a generalization of the common hypothesis in these previous studies: Is the size of the cumulative stock return a function of not only the amount of earnings news, but also of the timing of that news? For instance, does bad news have a smaller negative effect if that news is released some days or weeks ahead of the actual earnings announcement? As in the more recent studies, we use analysts' earnings forecasts to measure market expectations. Under this approach, current-quarter revisions to analysts' forecasts are assumed to reflect the timing of earnings news released which addresses selective disclosure. The regulation provides that when an issuer (firm), or person acting on its behalf, discloses material non-public information to securities market professionals and/or holders of the issuer's securities, it must make public disclosure of that information. 
by the firm, either publicly or privately.

\section{Data and Methodology}

\subsection{Data Construction and Measurement Issues}

Our study examines U.S. firms' quarterly earnings reports from 1987 through 2001. Data on both equity analysts' forecasts of earnings per share and actual earnings per share (EPS) are drawn from the I/B/E/S history and analyst detail files. For each firm-quarter observation, we compute the average of analysts' quarterly EPS forecasts, measured in dollars per share, at three points in time: (i) 7 days after the previous quarter's report (or about twelve weeks before the current-quarter report date); (ii) 42 days (or six weeks), before the current-quarter report date; and (iii) 3 days before the report date. To avoid using stale forecasts, average forecasts are computed using only those forecasts that were issued or confirmed after the previous quarter's earnings report. To filter out observations where information timeliness may be a problem, we exclude firm-quarters in which earnings are not reported within 90 days after quarter-end. In addition, we exclude observations in which the report is not issued between 8 and 16 weeks after the previous quarter's earnings report (where the mode is about 13 weeks).

These data are used to construct our main information variables. We define the total forecast error as the difference between actual quarterly EPS, revealed on the announcement date, and our earliest consensus forecast, F0 in figure 1. Similar to BGH, we split the total forecast error into two components: (i) the surprise, defined as the difference between actual earnings and the consensus forecast 3 days earlier, $F_{2}$; and (ii) the forecast revision, defined as the difference between the 3-day forecast, $F_{2}$, and the early-quarter consensus forecast, $F_{0}$.

A key methodological question concerns the timing of the early forecast, $F_{0}$ : How early should this measurement be taken? BGH measure this as early as 3 days after the previous 
quarter's announcement. However, early in the quarter it is possible that analysts have not fully incorporated the ramifications of the previous quarter's official earnings release into their updated or reconfirmed forecasts, even if the stock price has incorporated that information. If this were the case, then revisions to these forecasts may not convey as much information to the market (where the news has already been digested) as revisions that follow new company guidance later in the quarter. This would create a spurious asymmetry in the magnitude of stock price responses to forecast revisions and announcement-day surprises.

To address this concern, we construct an alternative measure of the initial forecast revision, equal to the average forecast as of six weeks (42 days) prior to the actual earnings announcement, denoted by $F_{1}$ in figure 1 . In this case, the revision is the difference between $F_{1}$ and $F_{2}$, while the surprise is defined as before. For the typical firm, $F_{1}$ would fall in the middle of the third month of the quarter, about the time that most managers would have an accurate picture of the firm's performance over the first two months of the quarter. Also, most warnings tend to come near the end of the quarter or shortly thereafter, so this more abbreviated forecast revision period should capture most of the information released in pre-announcements (Soffer et al. (2000)).

A second measurement issue that we consider is how to best scale earnings revisions and surprises. The most common scale factor in the literature is the firm's beginning-of-period stock price. This scale factor is convenient because the stock price is always positive and is rarely small relative to the numerator. From an analytical perspective, however, this approach is less satisfying, and we also argue that this scale factor is likely to distort the relative sizes of earnings revisions and surprises across firms. In particular, it has been argued that the stock return of high growth, high price-to-earnings (PE) ratio firms should be more sensitive to any given earnings surprise compared to slower growing, low-PE firms. However, all else equal, scaling earnings revisions by stock prices will make the news on high-price firms appear smaller than the same news on low-price firms. If so, this scaling would induce measurement error that would reduce the apparent explanatory power of earnings news. 
Two alternative scale factors that we consider are the level of realized earnings-pershare, which converts the revisions and surprises into percentage terms, and book value per share, which converts them into returns on equity. While these measures might be preferable analytically and theoretically, they produce numerical difficulties when earnings or book value are negative or near zero. To implement these scale factors, we use their absolute values, and delete observations for which the value of the scale factor is close to zero. For the EPS scale factor, we omit observations in which actual EPS is 5 cents or less in absolute value, denoting the resulting variable by $|\mathrm{EPS}|$. In the case of book value, we omit observations where the absolute value of the expected quarterly return on equity was greater than 25 percent (an annualized expected return of 100 percent). ${ }^{2}$ Because the book value scaling factor produced results that were qualitatively indistinguishable from the |EPS| scaling factor, in what follows we discuss only the results based on the $|\mathrm{EPS}|$ and price scaling factors.

The earnings data are linked with stock price data drawn from CRSP. For each firmquarter, we calculate the cumulative return on the firm's stock between the day of the initial forecast, $F_{0}$, through the day after the release of the current quarter's earnings. To compute abnormal returns, we calculate the cumulative return on the S\&P500 Composite index over the same period and subtract this from the firm-level return. Although not shown in the paper, we also calculated abnormal returns using estimated betas in a traditional singlefactor market model. However, both the qualitative and quantitative results using these measures were virtually indistinguishable from the results reported here. ${ }^{3}$

\footnotetext{
${ }^{2}$ We drew the book value data from Compustat.

${ }^{3}$ We constructed betas for each firm-quarter using daily stock returns for the 250 trading days preceding the first calculation of the mean EPS forecast for each firm, matched with daily returns on the S\&P 500 index (the "market" return) over the same time period. In other words, for each firm we compute quarterly betas on rolling one year samples of the firm's stock returns and S\&P 500 returns. The principal reason that beta-adjusted returns do not change our results appears to be the fact that betas contain little predictive power for firm-level returns, particularly for smaller firms.
} 


\subsection{Sample Statistics}

After merging the I/B/E/S, CRSP, and Compustat data, constructing the revision, surprise, and abnormal return variables, and applying our data timeliness criteria, we have 134,098 firm-quarter observations (before scaling revisions and surprises). For most of our analysis, we split the data into two subsamples, an early sample spanning 1987-1995, and a late sample spanning 1996-2001. Doing so should provide some indication of any longer-term behavioral changes. Because coverage of smaller firms has expanded over time, there are many more observations per quarter in later years.

We apply some additional criteria to eliminate outliers. We remove firm-quarters with a beginning-of-period stock price less than 3 dollars, as such observations are likely to produce very volatile and highly idiosyncratic returns. As mentioned earlier, for the earnings-scaled analysis, we eliminate observations in which quarterly EPS is 5 cents or less in absolute value. Lastly, we trim out observations for which any of the variables (revisions, surprises, or abnormal returns) have extreme values, defined as values in the top or bottom 2 percent of the variable's empirical distribution. After these refinements, we are left with a total of 100,437 observations in the sample using the $|\mathrm{EPS}|$ scaling factor, and 111,111 observations for the sample using the price scaling factor.

In order to provide a sense of some of the qualitative features of our data, figure 2 provides scatter plots depicting the joint distribution of "12-week" earnings revisions and earnings surprises, scaled by |EPS|. Panel A depicts the joint distribution over the period 1987-1995, while panel B shows the distribution for the period 1996-2001. In the early period, revisions range from -0.94 to 0.30 (-94 percent to 30 percent), while in the late period, revisions range from -108 percent to 21 percent. The distribution of surprises in the early period is more skewed toward negative surprises than in the late period. These features of the data are suggestive of increased efforts over time on the part of analysts to keep their forecasts current, and/or increased efforts on the part of firms to manage down expectations so as to 
avoid negative surprises. ${ }^{4}$

Turning to a quantitative description of the data, table 1 displays univariate statistics for our measures of revisions, surprises, and abnormal returns. The table displays the $25^{\text {th }}$, $50^{\text {th }}$, and $75^{\text {th }}$ percentiles for the variables, plus the interquartile ranges, with all values multiplied by 100 (which converts the dependent variable and the $|\mathrm{EPS}|$-scaled revisions and surprises into percent values). Panel A shows statistics for the early and late samples when the revisions and surprises are scaled by |EPS|, while panel B shows sample statistics when we scale by price. The first column in the upper left box of panel A shows some of the distributional characteristics of abnormal returns, the dependent variable, in the early period for the 12-week revision subsample. As shown, fifty percent of the observations on abnormal returns lie between -7.90 percent and 7.43 percent, and the median value is -0.18 percent. In the late period, abnormal returns appear more volatile, with the $25^{\text {th }}$ percentile at -13.00 percent and the $75^{\text {th }}$ percentile at 10.17 percent.

In both the early and late samples, there is a clear asymmetry in the distribution of revisions, with negative revisions being much larger and more plentiful than positive revisions. In the early sample, the $25^{\text {th }}$ percentile $\mid$ EPS $\mid$-scaled revision equals -5.15 percent, whereas the $75^{\text {th }}$ percentile is 1.67 percent. Although the late sample also shows this asymmetry, the distribution is notably tighter, implying that that quarterly forecasts have become more accurate in recent years.

Moving down panel A to the statistics for the 6-week forecast revisions, we find this narrower measure to be much more tightly distributed compared to the 12-week revisions, with a higher proportion of zeros. The $25^{\text {th }}$ percentiles fall to -1.71 percent and -1.14 percent in the early and late periods, respectively, while the median 6-week revision is zero in both subsamples.

More obvious here than in the scatterplots is the strong positive skew of surprises, consistent with the findings of previous studies, such as Richardson et al. (2003), which document

\footnotetext{
${ }^{4}$ The striations evident in the data reflect rounding and our cutoff on EPS values. We discuss the boxes below.
} 
analysts' generally positive forecast bias that disappears as the earnings announcement date nears. In the early sample, the median surprise is 1.08 percent, while in the late period, it is 2.34 percent. The positive skew in the distribution of surprises is most evident in the late sample, suggesting greater effort by firms to avoid negative surprises in recent years, consistent with the findings in Matsumoto (2002).

Turning to the price-scaled data in panel B, the qualitative features of the statistics differ only slightly from panel A. The small differences in the distributions of abnormal returns owe to the filtering out of observations with tiny earnings-per-share values.

The partial correlations amongst the variables can be inferred from table 2 , which shows the results of simple linear regressions estimated on the various subsamples, with abnormal return as the dependent variable. All three information variables - the two partly overlapping revision variables and the surprise — are included as regressors. The regression $\mathrm{R}^{2}$ values range between 4.8 and 6.2 percent, values comparable to those for similar regressions in previous studies. There appears to be little difference in qualitative comparisons between the results for the $|\mathrm{EPS}|$-scaled and the analogous price-scaled regressions.

Focusing on the |EPS|-scaled regressions, in both the early and late subsamples, all three information variables are significant, suggesting that the stock price effects of late-quarter revisions (those during the last six weeks before report) tend to be larger than the effects of revisions earlier in the quarter. In the early sample period, the coefficient on the 12-week revision is only 0.05 , while the marginal effect of the 6 -week revision is 0.23 ; this would imply that a revision during the latter six weeks has a total effect of $0.28(0.23+0.05)$. Notably, the coefficient on the surprise is only 0.16 , suggesting that surprises have a substantially smaller effect on returns compared to late-quarter revisions. However, we view these results as at best suggestive; given the potential for nonlinearities in the relationship between returns and revisions and surprises, they may not hold up over key portions of the revision-surprise space.

The late period results are similar, though the effects of our information variables appear 
to be larger. The coefficient on 12 -week revisions is substantially larger, at 0.21 , perhaps reflecting increased attentiveness toward early-quarter forecasts in more recent years. In this sample, the total estimated effect of forecast revisions during the second 6-week interval is $0.35(0.21+0.14)$. Finally, the coefficient on surprises, at 0.28 , is nearly twice as large as in the earlier years.

\subsection{Methodology: Locally Weighted Least Squares}

Our basic regression specification is given by:

$$
\text { Abnormal Return }_{n}=f\left(\text { Revision }_{n}, \text { Surprise }_{n}\right)+\epsilon_{n}
$$

for $n=1,2, \ldots, N$, where $N$ is the number of firm-quarter observations (note that we have pooled the quarterly data and dropped the time subscript for notational ease). The "Abnormal Return" on a firm's stock is the cumulative return over the roughly 12-week period ending one day after the earnings report, less the cumulative return on the S\&P500. The "Revision" and "Surprise" are defined as described above. ${ }^{5}$ The random error $\epsilon_{n}$ is assumed to be normally distributed with zero mean and constant variance $\sigma^{2}$, and is further assumed to be uncorrelated with revisions and surprises.

Theory provides little guidance on the functional form of $f(\cdot)$, so in order to allow for the greatest range of possible functional forms, we adopt a nonparametric estimation approach. Specifically, we employ locally weighted least squares (loess) to estimate $f(\cdot)$ (Cleveland (1979), Cleveland and Devlin (1988), Cleveland, Devlin and Grosse (1988)). Loess is essentially a method for smoothing scatterplots by means of the local fitting of low-order polynomials. At a given point in the revision and surprise space, local fitting is achieved with a weighting scheme that down-weights data points that are relatively distant from the given fitting point. Compared to perhaps more familiar kernel regression techniques, such

\footnotetext{
${ }^{5}$ In our notation, we do not explicitly indicate the scaling factor; in the discussion of our results, we will always make clear which scaling factor applies.
} 
as the Nadaraya-Watson estimator (Nadaraya (1964), Watson (1964)), loess is typically less biased on the boundaries of the data and in other situations where the data are asymmetrically distributed in the local regression sample (where by local regression sample we mean the points with non-zero weight in the local fit — see Hastie and Loader (1993)). Moreover, the estimator enjoys a number of convenient statistical features by virtue of its close association to the ordinary least squares estimator.

An important element of the loess methodology is the definition of the weighting function. Following Cleveland (1979), we employ the "tricube" weight function:

$$
W(x)=\left\{\begin{array}{rrr}
\left(1-|x|^{3}\right)^{3} & \text { for } & |x|<1 \\
0 & \text { for } & |x| \geq 1
\end{array}\right.
$$

As shown in Devlin (1986), the tricube weighting function improves certain approximations to the distributions of some of the statistics associated with the loess estimator. Denoting by $h_{i}$ the distance from $x_{i}$ to its $\mathrm{r}^{t h}$ nearest neighbor, for each data point $n=1,2, \ldots, N$ we construct the weights:

$$
w_{n}\left(x_{i}\right)=W\left(\frac{x_{n}-x_{i}}{h_{i}}\right)
$$

As can be seen by examining equations (2) and (3), the $\mathrm{r}^{\text {th }}$ nearest neighbor and all points more distant from $x_{i}$ receive zero weight.

The estimates $\hat{\beta}_{i, 0}$ and $\hat{\beta}_{i, 1}$ are computed by minimizing the sum of squared residuals:

$$
\sum_{n=1}^{N} w_{n}\left(x_{i}\right)\left(y_{n}-\beta_{i, 0}+\beta_{i, 1} x_{n}\right)^{2} .
$$

More independent variables can, of course, be included in equation (4), if called for in the application at hand. As we move across the fitting points $x_{i}$, we re-compute the weights assigned to each of the data points included in the regression, producing a series of estimates $\hat{\beta}_{i, 0}$ and $\hat{\beta}_{i, 1}$ for $i=1,2, \ldots, N$.

Like all other nonparametric techniques, an application of loess requires that the econo- 
metrician decide on the degree to which the precision of the estimate (bias) is to be traded off against smoothness (variance). In general, the desired amount of smoothing is applicationspecific (Mallows (1973)). We based our smoothing parameter selections on two standard selection methods. First, we performed generalized cross-validation (GCV) on each subsample in order to select a smoothing parameter (Härdle (1990)). Second, we computed M-statistics across a range of smoothing parameter settings. As discussed in Cleveland and Devlin (1988) and summarized in the appendix, the M-statistic is an extension of the $C_{p}$ procedure of Mallows (1973) for choosing a subset of independent variables based on estimates of the mean squared error for each subset. We used graphs of M-statistics (M-plots) to gauge the tradeoff between bias and variance embodied in the smoothing parameter selected by GCV. In general, the M-plot analyses confirmed the GCV smoothing parameter settings: the M-plots revealed that the GCV parameters were consistent with a null hypothesis of zero bias. In cases where there was divergence between the GCV parameters and the optimal parameter suggested by the M-plot analysis, we picked the lowest smoothing parameter (least smoothing) that would accept a null hypothesis of zero bias at the traditional 95 percent level, so as to reveal nonlinearities in the abnormal return response function.

\section{Empirical Results}

We begin by estimating the effects of 12-week forecast revisions and earnings surprises, both scaled by $|\mathrm{EPS}|$, on abnormal returns in the early sample period (1987-1995). Figure 3 shows four sets of estimation results, each based on a different smoothing parameter. The upper left plot depicts the estimated surface for a smoothing parameter setting of 0.15 , meaning that each local regression uses 15 percent of the available data. At the other extreme, the bottom left plot shows the estimated surface based on a smoothing parameter of 0.75 . We display the surfaces over a portion of revision and surprise space that contains most of the data. For this subsample, the displayed surfaces are on a grid of points laid over the box 
drawn in panel A of figure 2. ${ }^{6}$ The rest of the surface is omitted because the quality of the fit deteriorates as we move toward the fringes of the data.

Each surface shows the predicted abnormal return in the relevant revision-surprise space. As one would expect, the surface tends to be highest where both the revision and surprise are positive and relatively large. Casual observation suggests that the predicted abnormal return is an increasing function of the revision and surprise over most of the sample space. But the results also indicate substantial nonlinearities; in particular, the effect of a change in the revision or surprise appears to be largest when both are close to zero. Of course, the degree of nonlinearity is reduced when the surface is estimated with a high smoothing parameter, but the GCV smoothing parameter for this sample is low, about 0.15.

Figure 4 illustrates the results from the same estimation procedures run on the later sample period (1996-2001). ${ }^{7}$ These surfaces clearly slope upward over the whole range of the data in both the revision and surprise dimensions, and differ from the early sample in two notable respects. First, there appears to be less nonlinearity: changes in either independent variable have a noticeable price impact over the entire range of the independent variables, rather than effects that are concentrated near $(0,0)$. The optimal smoothing parameter reflects this fact; our selection methodology picked an optimal smoothing parameter of 0.6, much higher than in the early sample. Second, while somewhat difficult to discern, the range of predicted abnormal returns in this sample (the vertical range of the surface) is wider than that in the early sample, implying that the stock price sensitivity to earnings surprises has increased over time.

A useful tool for gauging the relative effects of revisions and surprises is the contour plot, a two-dimensional plot of iso-return lines in revision-surprise space. Figure 5 provides such a contour plot for the early-sample estimates shown in figure 3 (at the optimal smoothing parameter setting of about 0.15). The iso-return lines (the solid curved lines) reflect 1

\footnotetext{
${ }^{6}$ In each case, the box over which the surfaces are displayed covers the $4^{\text {th }}$ through $96^{\text {th }}$ percentiles in the revision dimension and the $6^{\text {th }}$ through $94^{\text {th }}$ percentiles in the surprise dimension. Twenty points in each dimension are plotted, for a total of 400 points on each surface.

${ }^{7}$ The surfaces are displayed over the box drawn in panel B of figure 2.
} 
percentage point steps: moving from one iso-return line to an adjacent line corresponds to a 1 percentage point change in abnormal return. The highest iso-return lines are in the upper right-hand corner, where both the revision and surprise are positive. The distance of the iso-return lines from one another indicates the return gradient in a particular direction; more tightly packed contour lines indicate a larger effect of earnings information on abnormal return.

If the timing of information matters, then changing the decomposition of a given total forecast error into surprise versus revision would put one onto a different iso-return line. In order to gauge the trade-off, we overlay three "iso forecast error" loci, represented by the straight dashed lines. Any given iso-forecast error locus represents the state faced by the firm, characterized by (i) the initial expectations at the beginning of the quarter and (ii) the earnings it will ultimately report. A particular position along that iso-forecast error line represents an information release policy by the firm. For instance, the lowest line, labeled -10 percent, represents the state in which the early-quarter analyst forecast, $F 0$, is 10 percent higher than the actual earnings, which the company will ultimately report in its earnings release after quarter-end. The coordinates $(0,-10)$ on this line represent the outcome in which no information is released early and a -10 percent surprise is revealed on the earnings announcement date. Alternatively, the coordinates $(-10,0)$ represent a -10 percent early revision and zero surprise; here, all of the information was revealed early, perhaps via a preannouncement. Another possible outcome is $(-20,10)$ : overly pessimistic information is preannounced, prompting a -20 percent forecast revision, and actual earnings then exceed the pre-report forecast by 10 percent.

The first key empirical result of our analysis is seen by comparing the slope of the isoforecast error lines with the slopes of the iso-return lines, or "information policy lines." Forecast revisions have smaller price effects than surprises if the information policy lines are steeper than the iso-return lines. In that case, a firm can achieve a higher return by releasing unfavorable information early, that is, by choosing a point to the northwest on 
the information policy line. Indeed, this is what we find in the region near $(0,0)$, where the data concentration is highest. Thus our initial set of estimates are consistent with previous results suggesting that firms might be able to engineer higher returns by beating down expectations early on and then releasing good news to the market on the announcement date. In particular, this result is consistent with the findings of Bartov et al. (2002) who use difference-in-means tests on a similar sample and similar definitions of revisions and surprises.

Figure 6 depicts the contour plot that results from running the same estimation procedure on the late sample, spanning the period 1996-2001. Here, we are led to the opposite conclusion. The picture shows that the firm's information policy lines either run parallel to the iso-return lines or even, in some data-rich areas of the design space, at a shallower slope. For instance, the zero-percent forecast error line crosses over to lower iso-return lines when moving northwest from $(0,0)$ to $(-10,10)$.

Before speculating on why the two time periods might differ, we examine the sensitivity of the results to our definition of the forecast revision period. As noted earlier, there tend to be relatively few earnings preannouncments early in the quarter (subsequent to the previous quarter's report). Hence a measure of the forecast revision based on early-quarter forecasts could produce a downwardly biased estimate of the stock price effects of analyst revisions induced by preannouncments. To eliminate this potential source of bias, we re-estimate the return response surfaces using the 6 -week forecast revision in place of the 12 -week revision. Figures 7 and 8 show the contour diagrams with the results for the early and late sample periods, respectively. Here, in both samples, we find no evidence of a favorable tradeoff from releasing negative information early. In fact, the iso-return contours in both cases tend to be a bit shallower than the information policy lines, which implies that the total effect of earnings news on returns may even be smaller in cases where firms kept the negative information under wraps until the earnings announcement.

Clearly, the estimates using the 6-week forecast revision produce no evidence to suggest 
that firms can bolster their stock prices by preannouncing bad earnings news early in order to meet or beat expectations when the earnings report is released. How do we reconcile these results and the somewhat ambiguous conclusions drawn based on the 12-week revision? First, as argued earlier, early-quarter forecasts by analysts may not reflect all of the information revealed to the market in the previous quarter's financial report. With similar effect, even if investors have not refined their own views on current-quarter earnings, they still might heavily discount analysts' early-quarter forecasts. Either way, movements in analyst estimates earlier in the quarter might not accurately reflect investor convictions.

Still, there remains the question of why the earlier 12-week revisions appear to have had more price impact in recent years, as implied in Figure 6. This might be rationalized by the observation that analysts' earnings forecasts have garnered increased attention over the 1990s, evidenced for instance by the increased use of analysts' forecast revisions as a factor in stock selection during this period (Kirschner and Bernstein (2003)). As their forecast revisions have garnered more attention in recent years, analysts presumably felt stronger incentives to exert greater effort in calibrating their early-quarter forecasts.

\subsection{Standard Errors}

The statistical precision of our conclusions is perhaps best cast in terms of the accuracy with which we can resolve the location of the contour lines on our contour plots. Hence, in terms of statistical precision, we are primarily concerned with the standard errors on the fitted values (the distribution of the standardized residuals) as opposed to the individual coefficient estimates.

Under the loess theory, the distribution of the standardized residuals is well approximated by a $t$-distribution. However, calculation of the degrees of freedom is computationally expensive (see Cleveland et al. (1988)), requiring the inversion of a matrix with rows and columns equal to the number of observations. Moreover, this matrix must be built up one row at a time because, in essence, there is a different set of regression coefficients at each 
fitted point. To make these calculations we developed specialized software based on the Scalapack software library. ${ }^{8}$

Table 3 provides calculations of the precision of our fit for the late sample period. ${ }^{9} \mathrm{We}$ display the width of 95 percent confidence intervals around the fitted values at various points on the solution surface. Panel A displays the confidence interval widths when we use the 12-week revision. As can be seen, in the center of the data (near the point where both the revision and surprise are zero), the confidence intervals have a width of about 1.3 percentage points of abnormal return. When we move to the outer fringes of the data, where the observations are far less concentrated, the confidence interval widths range from 2.1 to 3.7 percentage points. Comparing these results to those in Panel B, we find that the widths of the confidence intervals in the center of the data are comparable when we use the 6-week revision, but at the fringes the confidence intervals are somewhat wider. Taken together, these results indicate that a two percentage point move, that is, a move across two contour lines, is a statistically significant move in the area where the data is densely distributed. This suggets that, in figures 6,7 , and 8, the perverse tradeoffs that we find for firms moving along their information policy lines are only statistically significant for fairly sizable moves, if at all. Our results on statistical precision also indicate that, as one moves further away from the center of the data, the contours are not resolved with as much statistical precision, suggesting some caution is required in interpreting the shape of the contours in regions where the data are relatively sparse.

\subsection{Robustness and Sub-Sample Analysis}

This section explores the robustness of our qualitative results, focusing in particular on the findings for the 6-week revision period. As discussed earlier, our main concern is the sensitivity of the results to the choice of the scaling factor for the earnings news. To examine

\footnotetext{
${ }^{8}$ The Scalapack library contains pre-programmed Fortran and $\mathrm{C}$ routines for carrying out basic linear algebra computations on a network of workstations.

${ }^{9}$ Calculations for our other fits reveal similar degrees of precision, and are omitted.
} 
this issue, we re-estimate the early- and late-period contours with the revision and surprise variables scaled by price. The results are shown in Figures 9 and 10. The optimal smoothing parameters used to estimate these contours are low, particularly the 0.10 used for the early period, which compares to the value of 0.15 used in the earnings denominator specification. Consistent with the low smoothing parameter, the contours for the early sample suggest a high degree of nonlinearity, with a large portion of the vertical climb being concentrated around the zero-surprise line. In contrast, the contours for the late-period are much more evenly spaced, suggesting less nonlinearity.

While the evidence of nonlinearities seems clear, we find no substantive evidence of any benefit from getting bad news out early. This is most obvious in the late-sample estimates. In the early-sample estimates, this judgment requires more careful scrutiny. As shown in figure 9 , there appears to be no net benefit from moving along the -.002 forecast-error locus, for instance, from the zero revision to the zero surprise point. While moving further up the locus (into negative revision and positive surprise territory) does appear to produce some benefit, the gain is small and statistically insignificant. Finally, we note that, as shown in the appendix, the $\mid$ EPS $\mid$ scaling factor produces somewhat better fits to the data, at least as judged using the Akaike Information Criterion (AIC) values for the |EPS|-scaled fits compared to the fits scaled by price.

So far, the analysis ignores any potential role of heterogeneity, that is, the likelihood that sensitivity to earnings news differs systematically across firms. This may be particularly important if such differences induce substantial variation in the propensity to play the consensus-meeting game. For instance, Skinner and Sloan (1999) provide evidence suggesting that stocks of high-growth firms are more vulnerable to negative earnings surprises, due to their high valuations being so dependent upon investors' optimistic expectations for earnings growth. If so, these firms might be more prone to prerelease bad news than low-growth firms. Moreover, investor awareness of such different propensities might influence how the market reacts to news. In particular, firms that habitually warn and then meet or beat expectations 
or those that have not met expectations in recent quarters might face a different tradeoff in the current quarter than firms that recently reported negative surprises.

While it is unclear how such heterogeneity might bias our conclusions, we can examine the robustness of our results by splitting the sample along some potentially important dimensions. This approach is used principally because computational and data constraints limit our ability to expand the dimensionality of the estimation, although it does have the advantage of allowing for very general qualitative comparisons. Two firm characteristics that we consider are: (i) firm size, gauged by market value; and (ii) firm growth prospects, gauged by the median of analysts' long-term growth forecasts. Firm size may be an important factor because, all else equal, larger firms tend to have more predictable earnings. Moreover, such firms have a broader following in the investment community, and analysts may do a better job of forecasting their earnings. Casual observation of press reports suggests that the very largest firms devote a relatively high level of resources toward managing market expectations. As mentioned earlier, firm growth prospects have been shown to correlate with the sensitivity of stock price to earnings news. ${ }^{10}$

We perform a two-by-two sample split along the firm size and growth dimensions, producing four subsamples: large/high growth, large/low growth, small/high growth, and small/low growth. The size split is based on beginning-of-quarter market value. A firm is assigned to the large-firm subsample if its market value is above the median firm's market value in the same quarter. This produces a split that is balanced over time; the small-firm group does not shrink over time due to the upward trend in nominal firm valuations. The growth split is based on the sample median growth forecast. A firm is assigned to the high-growth subsample if its analysts' average long-term growth forecasts are above the sample median.

Figure 11 displays fitted surfaces for the four subsamples based on their optimal smoothing parameters. Noting that the vertical axes differ markedly across the subsamples, the

\footnotetext{
${ }^{10}$ We have explored whether the number of analysts following a firm affects our results. Specifically, we imposed a lower limit on the number of analysts tracking a firm in order for the firm to be included in the sample, and re-ran all of our calculations. Our results were not affected in a material way by this type of restriction.
} 
estimated surfaces for high growth firms (the two bottom figures) are much steeper than those for the set of low-growth firms (the two top figures). This indicates that earnings news can explain more stock return variance for high-growth firms than for low-growth firms. Moreover, since the horizontal axes for the high- and low-growth results cover similar ranges, the steeper slope also implies that a given magnitude of earnings news tends to have a larger impact on high-growth firms' stock prices. In contrast, comparing the small and large samples while holding the growth class constant, it appears that smaller firms experience a wider range of earnings news; in particular, they experience more extreme negative surprises and revisions than large firms.

The associated contours are shown in figure 12. The top row of figures again displays the contours for the low-growth firms, small and large. As in the overall sample, bringing out bad news early does not appear to produce any net benefit for those firms, and in many instances appears to be counter-productive. However, this finding is a bit more nuanced for at least one of the subsamples. Consider the large low-growth firm contours. Moving along the negative -0.10 (negative 10 percent) forecast error locus, from zero revision $(0,-0.10)$ to zero surprise $(-0.10,0)$ appears to reduce stock returns on average by 2 percent. However, the concave-shaped contours imply that this is the worst place to be. Moving up from (-0.10, $0)$ to $(-0.25,0.15)$ appears to boost return 2 percent, which suggests that it may be better to exaggerate the possible shortfall than to warn and then just meet revised expectations, at least in this case.

The results for the other three subsamples suggest that the trade-off from preannouncing news is at best neutral over the vast majority of the surprise/revision space. This result comes through quite clearly in the case of large high-growth firms. This is the group of firms that is probably most prone to playing the consensus-meeting game, and, as evidenced by their more tightly-packed contours, their stock prices are much more sensitive to earnings news compared to their low-growth counterparts discussed above. The most interesting group, however, may be the small high-growth firms. For these firms, the figure shows 
about 35 contour lines (35 percentage points of return variation), which implies that earnings forecast errors explain a large range of abnormal returns. The contours also reveal substantial nonlinearity; the tightly packed lines in the region just to the southwest of $(0,0)$ indicate

that relatively small negative revisions as well as small negative surprises have particularly strong, albeit symmetric, effects on stock returns.

We end our search for the timing effect by conditioning our sample split on firms' recent surprise histories. In one group, we include only firms that did not have a negative surprise in either of the two preceding quarters; the second group contains all other firms, that is, firms with one or two negative surprises in the previous two quarters. As shown in panels A and B of figure 13, this sample split again confirms the robustness of our earlier results. The scale ranges on the surprise axis of the contours do indicate that firms with a recent negative surprise are more prone to issue a negative surprise again. However, we find that neither group of firms appears to benefit by preannouncing negative news in order to meet expectations at the time of report.

\section{Conclusion}

In this paper, we examined the stock price benefit of meeting or beating earnings expectations. We estimated the effect of quarterly earnings news on quarterly stock returns by splitting analysts' total forecast errors into a forecast revision and an earnings surprise. We then estimated the effects of these forecast revisions and earnings surprises on the cumulative abnormal return over the period.

The most important methodological difference between our study and previous studies is our use of loess, a nonparametric estimation technique that allows for a wide range of functions that map earnings news into abnormal returns. A second important methodological consideration in our analysis is the econometrician's choice of the "preannouncement period." We conjecture that revisions early in the quarter might be contaminated by the previous 
quarter's news, which could create a spurious asymmetry in the magnitude of stock price responses to forecast revisions and earnings surprises. Finally, we examined the choice of the scaling factor applied to the forecast revisions and surprises.

In contrast to previous studies, we did not find persuasive evidence of a short-term stock price benefit to preannouncing bad news; that is to say, we found little or no difference in the sensitivity of stock returns to early forecast revisions and earnings surprises. Our nonparametric approach does uncover significant and fairly interesting nonlinearities. In particular, we find that the sensitivity of returns to earnings news tends to get stronger when the news is close to zero. Moreover, this would appear to be true regardless of whether the news is reflected in revisions or surprises.

There is one notable case where we do find evidence consistent with the hypothesis that firms benefit by getting bad news out early. When we estimate the response function using the longer revision period, on the 1987-1995 subsample, surprises appear to have a larger effect on returns than revisions over an important part of the sample space. However, when the model is estimated using a shorter (6-week) revision period, when more of the revisions are presumably driven by preannouncements, the asymmetric response disappears. Moreover, when we estimate the response function on the post-1995 sample, this result is again reversed, regardless of the definition employed for the revision period.

An appealing interpretation that reconciles these results is that, in earlier years, equity analysts may not have been particularly diligent about reworking their quarterly earnings forecasts following previous-quarter announcements. If so, then revisions over the earlier part of the quarter would have partly reflected information that may have already been incorporated into stock prices. However, as quarterly earnings forecasts garnered increasing attention during the 1990s, analysts may have become more assiduous about updating their current-quarter estimates.

We further examined the issue by splitting the sample into subgroups by size and earnings prospects. Again, we found little evidence of an asymmetric stock return response to 
the timing of news. However, for large, low-growth firms, it does appear to be better to exaggerate any possible earnings shortfalls than to warn and just meet expectations. Finally, we conditioned on firms' recent surprise histories to see if firms with a track record of negative surprises, or a track record of meeting expectations, might face asymmetric stock return responses. Again we found no evidence of an asymmetric response.

The absence of any short-term stock price benefit from getting bad news out early begs the question: Why do firms manage their news releases? A definitive answer is beyond the scope of this paper, but a few comments are in order. First, it is possible that individual managers might believe that such actions will produce a near-term benefit to their stock price even if, on average, this is not the case. Indeed, if researchers in possession of the comprehensive data can not agree on the stock price benefits, should we expect managers, focused largely on their own firm's experience, to know the average effect? Second, the absence of any clear short-term benefit does not rule out the possibility of a longer-term reputational benefit. As pointed out earlier, both Chevis et al. (2002) and Liu and Yao (2003) provide evidence to suggest that firms that habitually meet expectations tend to be more highly valued, that is, have a higher stock price level given fundamentals. A comparison of short run returns probably has little power as a test of such longer-term valuation benefits.

In closing, it is worth reemphasizing that a variety of rationales that do not presuppose any benefit to quarterly stock returns have been proposed to explain this behavior. In fact, the hypothesis of Aboody and Kasznik (2000), that management is motivated to warn by the desire to receive stock option grants when their stock price is relatively low, is perhaps even more plausible in light of our findings. Furthermore, managers that intend to sell shares after the end of a "quiet period" might also benefit directly by shifting the timing of bad news and the associated volatility along the lines suggested by Richardson et al. (2003). Finally, the traditional rationale for the early release of bad news - that management is striving to mitigate the risk of securities litigation — does not presuppose any short-term stock price benefit. 
Table 1: Univariate Statistics

The table displays univariate statistics for revisions, surprises, and abnormal returns. The table displays the $25^{\text {th }}, 50^{\text {th }}$, and $75^{\text {th }}$ percentiles for the variables, plus the interquartile ranges (labeled $75-25$ ), with all values multiplied by 100 .

Panel A: |EPS| scaling factor

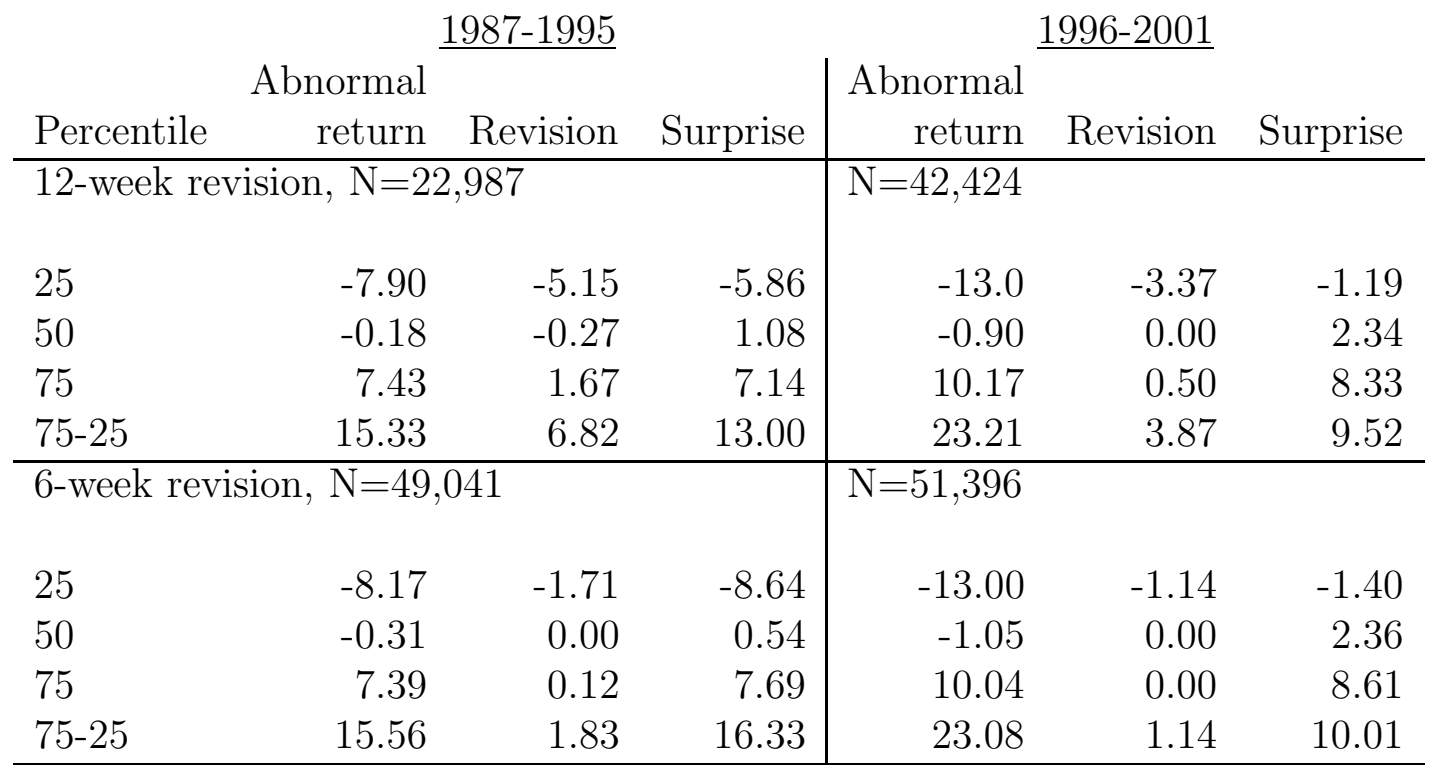

Panel B: Price scaling factor

\begin{tabular}{lrrr|rrr} 
& \multicolumn{3}{c}{$\underline{1987-1995}$} & & \multicolumn{3}{c}{$\underline{1996-2001}$} & \\
Percentile & $\begin{array}{c}\text { Abnormal } \\
\text { return }\end{array}$ & Revision & Surprise & $\begin{array}{r}\text { Abnormal } \\
\text { return }\end{array}$ & Revision & Surprise \\
\hline 12 -week revision, N=25,029 & & & $\mathrm{N}=46,986$ & & \\
25 & -8.35 & -0.10 & -0.12 & -13.9 & -0.06 & -0.02 \\
50 & -0.49 & -0.01 & 0.01 & -1.24 & 0.00 & 0.03 \\
75 & 7.38 & 0.03 & 0.12 & 10.15 & 0.01 & 0.12 \\
$75-25$ & 15.73 & 0.12 & 0.23 & 24.00 & 0.06 & 0.14 \\
\hline 6 -week revision $, \mathrm{N}=54,005$ & & & $\mathrm{~N}=57,106$ & & \\
25 & -8.77 & -0.03 & -0.18 & -14.0 & -0.02 & -0.03 \\
50 & -0.67 & 0.00 & 0.00 & -1.43 & 0.00 & 0.03 \\
75 & 7.24 & 0.00 & 0.13 & 9.99 & 0.00 & 0.12 \\
$75-25$ & 16.01 & 0.03 & 0.31 & 23.95 & 0.02 & 0.15 \\
\hline
\end{tabular}




\section{Table 2: Regressions of Abnormal Returns on Scaled Revisions and Surprises}

The table displays linear regression results for four variations of the basic specification

$$
\text { Abnormal return }=\beta_{0}+\beta_{1}(12 \text {-week revision })+\beta_{2}(6 \text {-week revision })+\beta_{3}(\text { Surprise })+\epsilon,
$$

with the revisions and surprises as defined in the main text. The regression is repeated for each scale factor over each sample period. The early subsample covers the period 1987-1995, while the late subsample covers the period 1996-2001. The sampling frequency is quarterly. The $t$-values displayed beneath each estimate are based on heteroscedasticity-robust standard errors. The sample sizes are smaller than those displayed in table 1 owing to the inclusion of both revision variables; observations missing either variable are dropped from the regression.

\begin{tabular}{ll|rrrr|rr}
\hline Normalization & Period & $\beta_{0}$ & $\beta_{1}$ & $\beta_{2}$ & $\beta_{3}$ & $\mathrm{~N}$ & $\mathrm{R}^{2}$ \\
\hline $\mid$ EPS & Early & 0.00 & 0.05 & 0.23 & 0.16 & 19,259 & 0.060 \\
& & 3.48 & 4.12 & 11.79 & 25.22 & & \\
& Late & -0.02 & 0.21 & 0.14 & 0.28 & 35,825 & 0.048 \\
& & -16.94 & 12.42 & 5.99 & 26.49 & & \\
\hline Price & Early & 0.00 & 2.91 & 14.43 & 9.34 & 20,971 & 0.062 \\
& & 0.12 & 4.94 & 13.25 & 26.87 & & \\
& Late & -0.02 & 14.17 & 9.80 & 17.83 & 39,605 & 0.051 \\
& & -19.37 & 13.91 & 6.92 & 28.60 & & \\
\hline
\end{tabular}


Table 3: Width of 95 Percent Confidence Intervals across Solution Surface

The table displays the widths of 95 percent confidence intervals at the indicated points on the solution surface. For example, in panel A, when the 12 -week revision is -0.05 (-5 percent) and the surprise is -0.05 , the width of the 95 percent confidence interval around the fitted value is 0.024 (2.4 percentage points wide). The width of the confidence intervals across the solution space indicates the degree to which the contours shown on the relevant contour plot can be differentiated. The confidence intervals are for the late sample period (1996-2001) using the |EPS| scaling factor; the widths of the confidence intervals for our other fits are similar in magnitude.

Panel A: 12-week revision

\begin{tabular}{r|rrr} 
& \multicolumn{3}{c}{ Revision } \\
\cline { 2 - 4 } Surprise & -0.05 & 0.00 & 0.05 \\
\hline 0.05 & 0.024 & 0.014 & 0.027 \\
0.00 & 0.021 & 0.013 & 0.034 \\
-0.05 & 0.024 & 0.020 & 0.037 \\
\hline
\end{tabular}

Panel B: 6-week revision

\begin{tabular}{r|ccc} 
& \multicolumn{3}{c}{ Revision } \\
\cline { 2 - 4 } Surprise & -0.05 & 0.00 & 0.05 \\
\hline 0.05 & 0.030 & 0.014 & 0.037 \\
0.00 & 0.026 & 0.012 & 0.048 \\
-0.05 & 0.027 & 0.017 & 0.052 \\
\hline
\end{tabular}


Figure 1: Decomposition of Total Forecast Error into Revision and Surprise

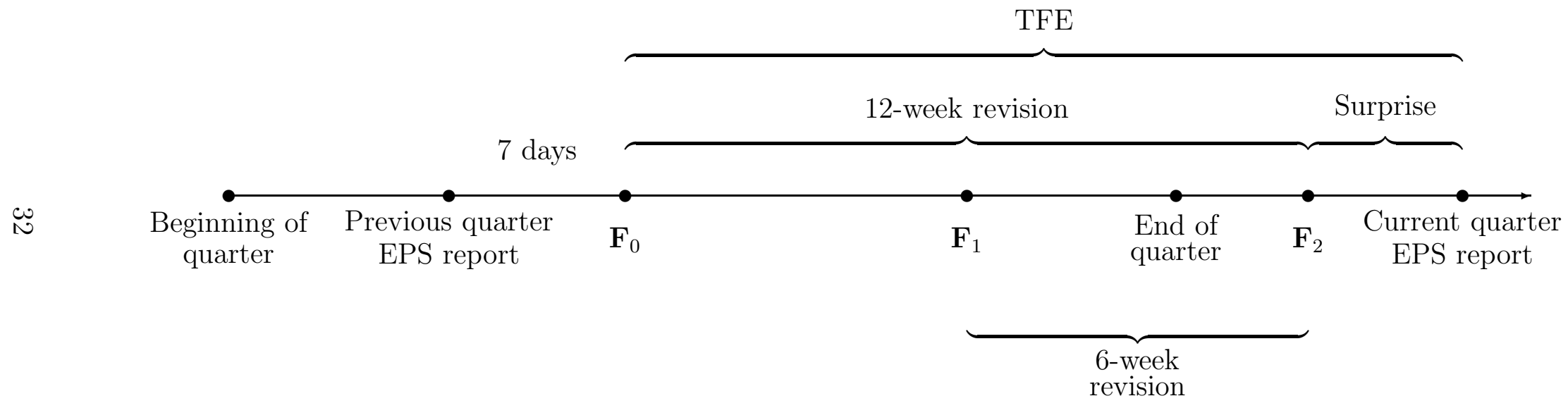


Figure 2: Scatterplots of 12-Week Revisions and Surprises

Panel A of the figure displays a scatterplot of revisions against surprises for the early period (1987-1995). The data are scaled by $|\mathrm{EPS}|$ and reflect our other data filters discussed in the main text. Panel B displays a scatter of revisions against surprises for the late period (1996-2001). The boxes in panels A and B show the regions plotted in figures 3 and 4 , respectively.

Panel A: Early Period (1987-1995)

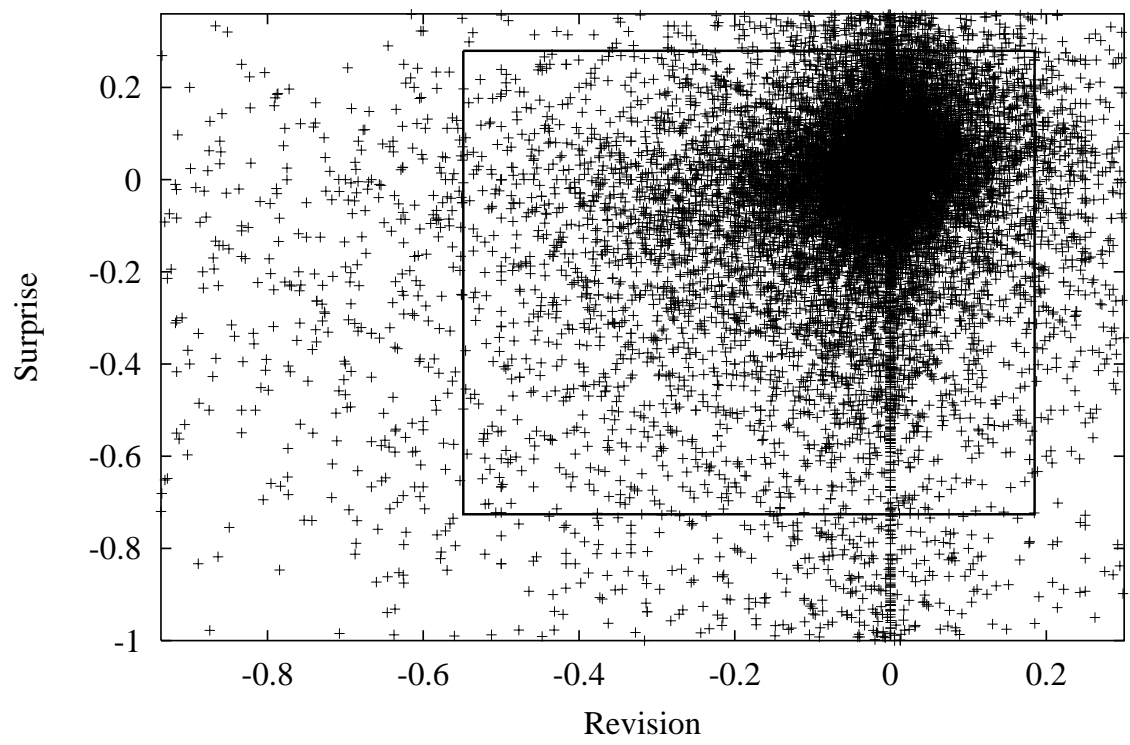

Displayed surface

Panel B: Late Period (1996-2001)

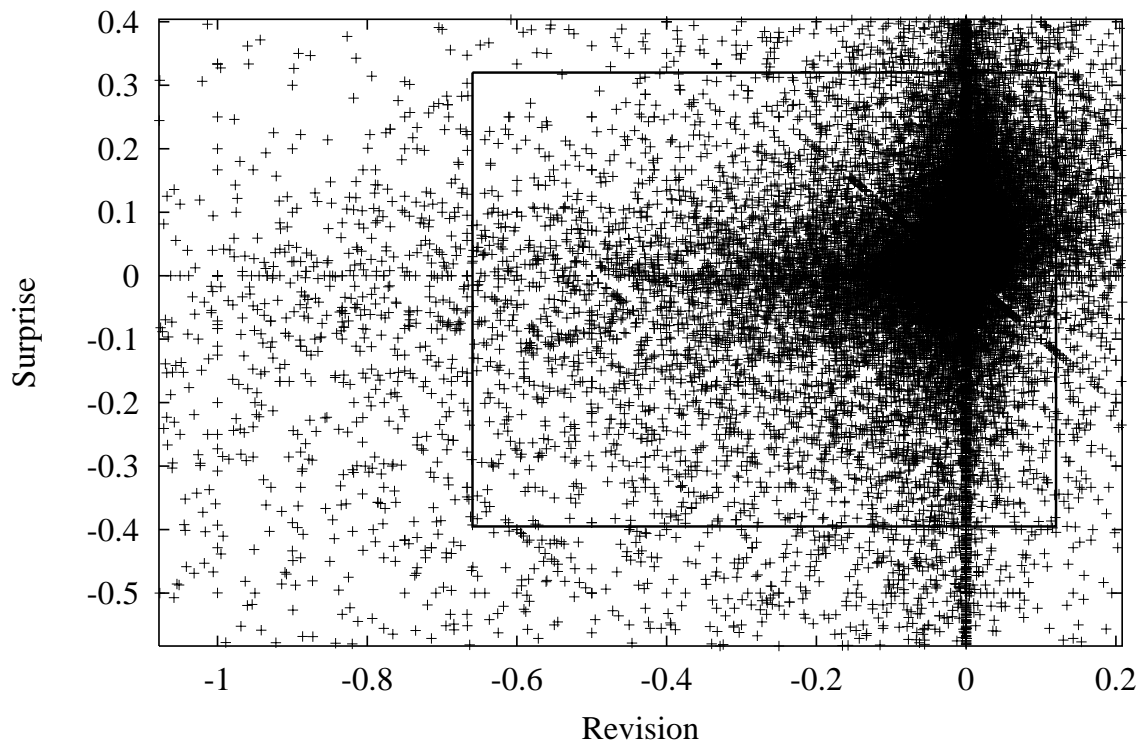

Displayed surface 


\section{Figure 3: Fitted Surfaces for 1987-1995 Period, |EPS| Scaling Factor}

The figure displays fitted surfaces for the early period subsample using the |EPS| scaling factor and the 12 week revision. The fitting method is locally weighted least squares, with each surface depicting the fit at the indicated smoothing parameter. The sample size is 22,987 .

Smoothing parameter $=0.15$

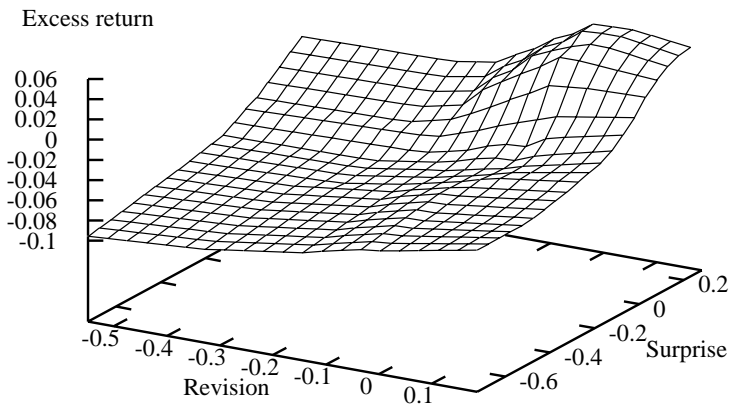

Smoothing parameter $=0.75$

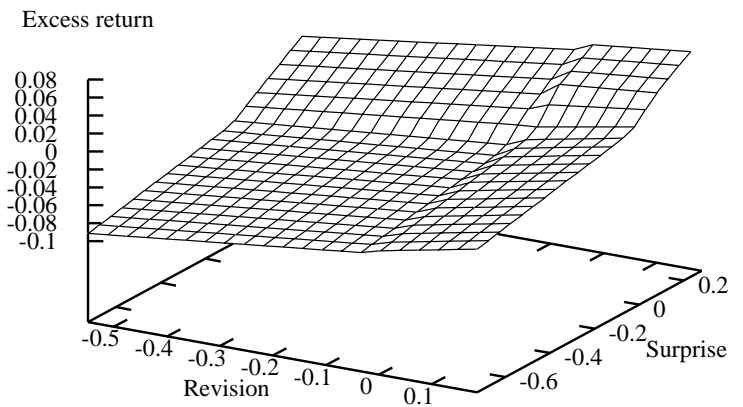

Smoothing parameter $=0.25$

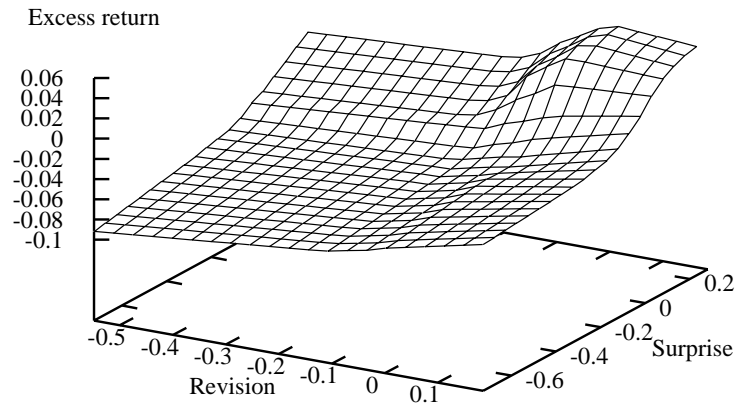

Smoothing parameter $=0.50$

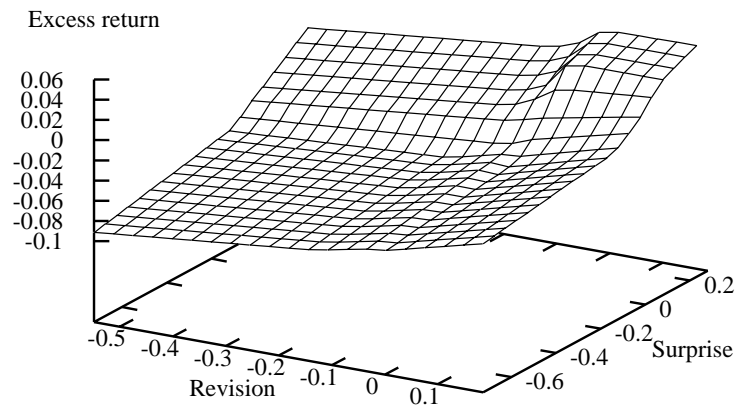




\section{Figure 4: Fitted Surfaces for 1996-2001 Period, |EPS| Scaling Factor}

The figure displays fitted surfaces for the late period subsample using the |EPS| scaling factor and the 12 week revision. The fitting method is locally weighted least squares, with each surface depicting the fit at the indicated smoothing parameter. The sample size is 42,424 .

Smoothing parameter $=0.15$

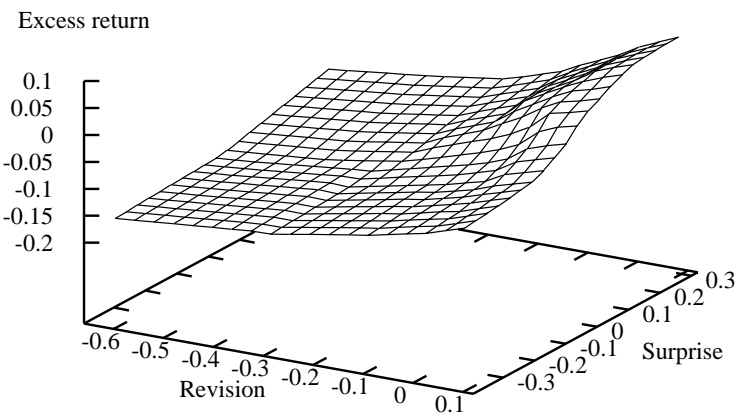

Smoothing parameter $=0.75$

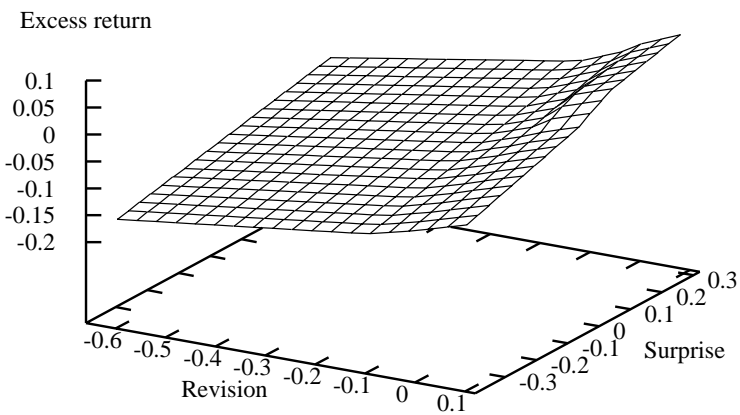

Smoothing parameter $=0.25$

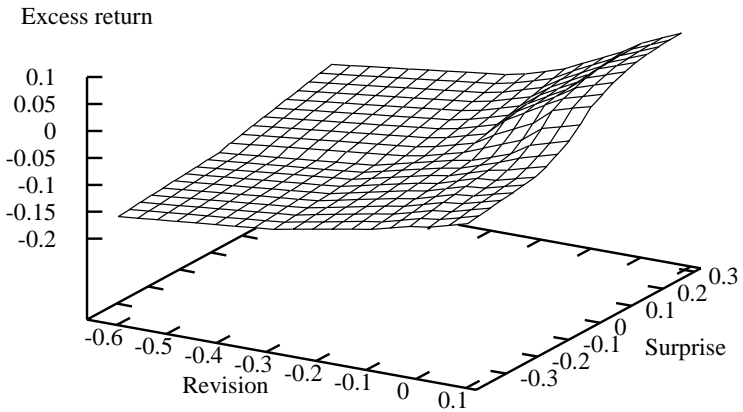

Smoothing parameter $=0.50$

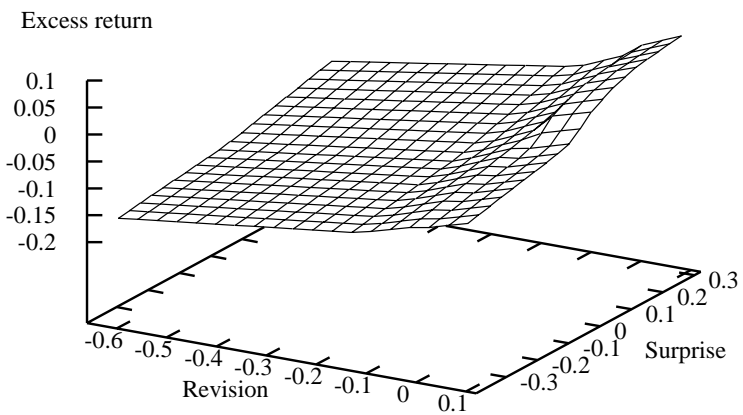




\section{Figure 5: Iso-Return Contours for 1987-1995 Period, |EPS| Scaling Factor}

The figure displays iso-return contours and three information policy lines. The fit is based on early-period data and the $|\mathrm{EPS}|$ scaling factor, and the revision is measured over a 12 week interval. The sample size is 22,987 firm-quarter observations and the optimal smoothing parameter is 0.15615 , determined by generalized cross-validation. The iso-return contours are spaced at one percentage point intervals; moving from a point on one contour to a point on an adjacent contour represents a one percentage point change in abnormal return. The information policy lines are for total forecast errors (TFE) of $0,-5$, and -10 percent. Movement along an information policy line represents an information release policy by the firm in terms of the timing of information release. Points to the northwest on a policy line represent a policy of releasing bad news in the revision period and good news in the surprise period.

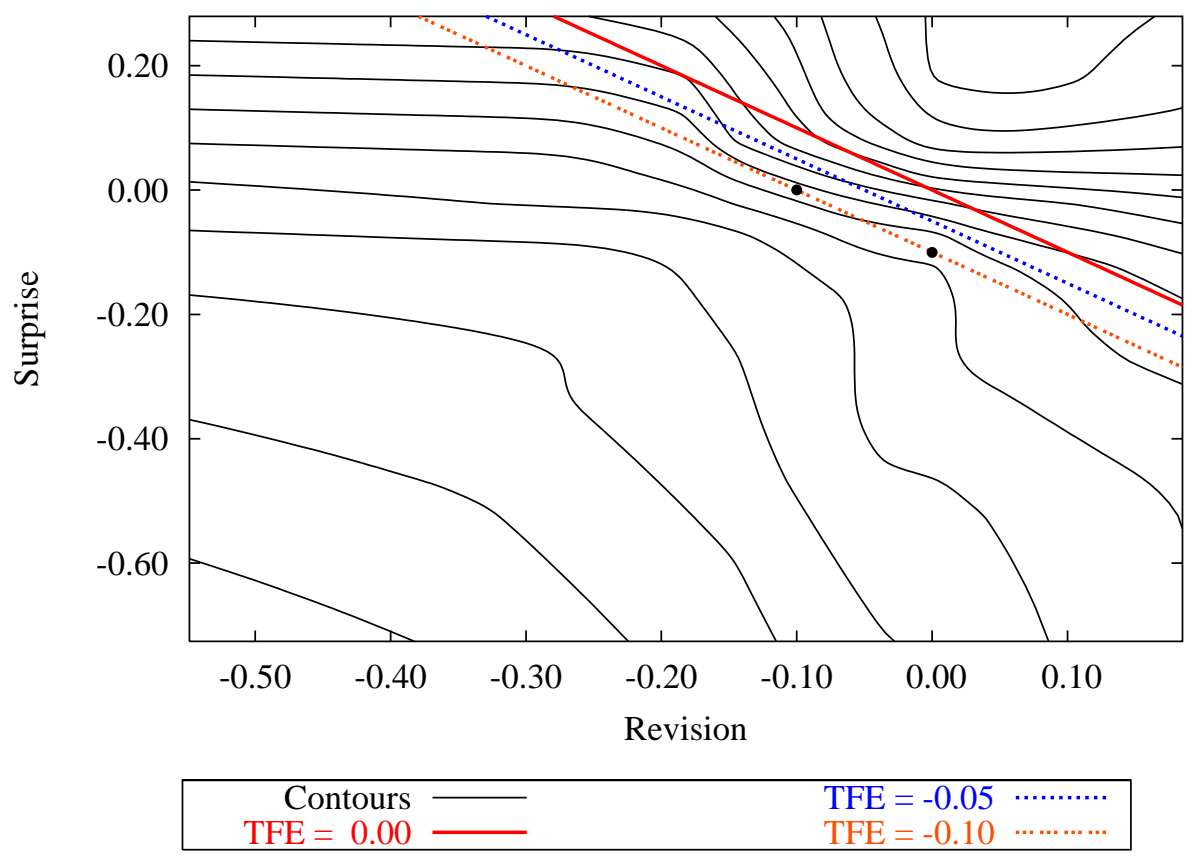




\section{Figure 6: Iso-Return Contours for 1996-2001 Period, |EPS| Scaling Factor}

The figure displays iso-return contours and three information policy lines. The fit is based on late-period data and the $|\mathrm{EPS}|$ scaling factor, and the revision is measured over a 12 week interval. The sample size is 42,424 firm-quarter observations and the optimal smoothing parameter is 0.62499 , determined by generalized cross-validation. The iso-return contours are spaced at one percentage point intervals; moving from a point on one contour to a point on an adjacent contour represents a one percentage point change in abnormal return. The information policy lines are for total forecast errors (TFE) of $0,-5$, and -10 percent. Movement along an information policy line represents an information release policy by the firm in terms of the timing of information release. Points to the northwest on a policy line represent a policy of releasing bad news in the revision period and good news in the surprise period.

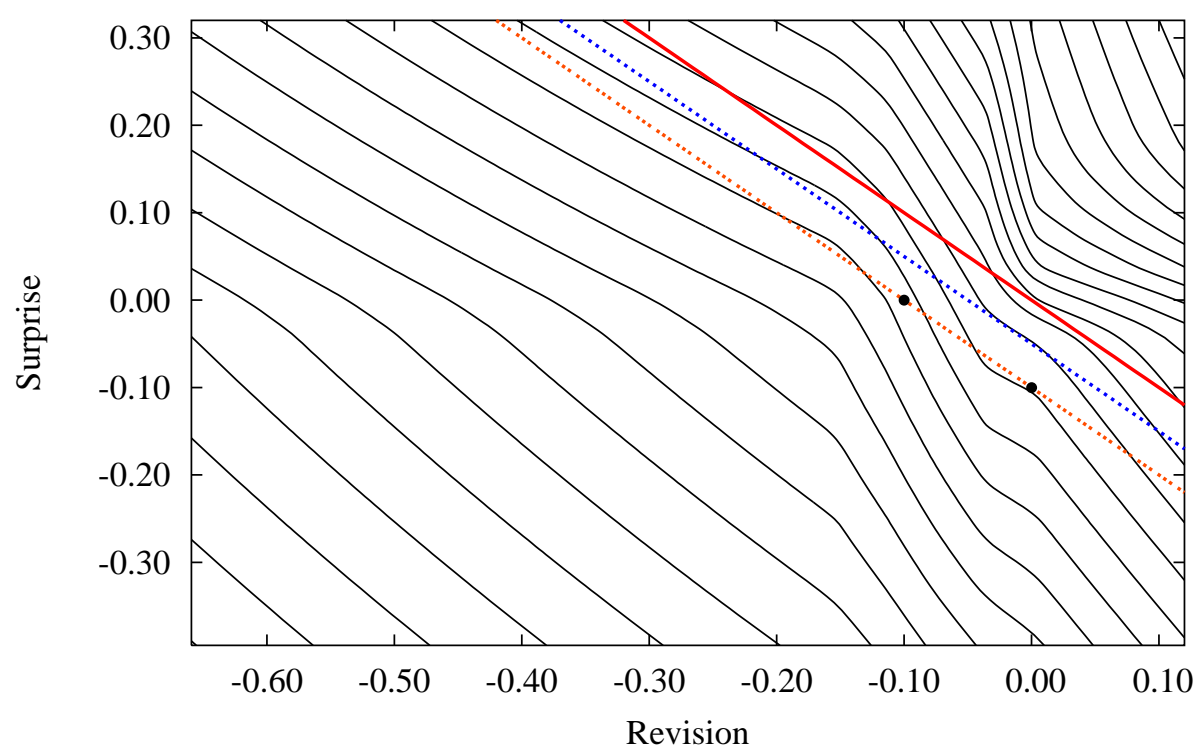

\begin{aligned} & Contours TFE $=-0.05 \quad \cdots \cdots \cdots \cdots \\ &$ TFE $=0.00$ TFE $=-0.10 \quad \cdots \cdots \cdots \cdots \\ &$\hline\end{aligned}


Figure 7: Iso-Return Contours for 1987-1995 Period, 6-Week Revision, |EPS| Scaling Factor The figure displays iso-return contours and three information policy lines. The fit is based on early-period data and the $\mid$ EPS $\mid$ scaling factor, and the revision is measured over a 6 week interval. The sample size is 49,041 firm-quarter observations and the optimal smoothing parameter is 0.15619 , determined by generalized cross-validation. The iso-return contours are spaced at one percentage point intervals; moving from a point on one contour to a point on an adjacent contour represents a one percentage point change in abnormal return. The information policy lines are for total forecast errors (TFE) of $0,-5$, and -10 percent. Movement along an information policy line represents an information release policy by the firm in terms of the timing of information release. Points to the northwest on a policy line represent a policy of releasing bad news in the revision period and good news in the surprise period.

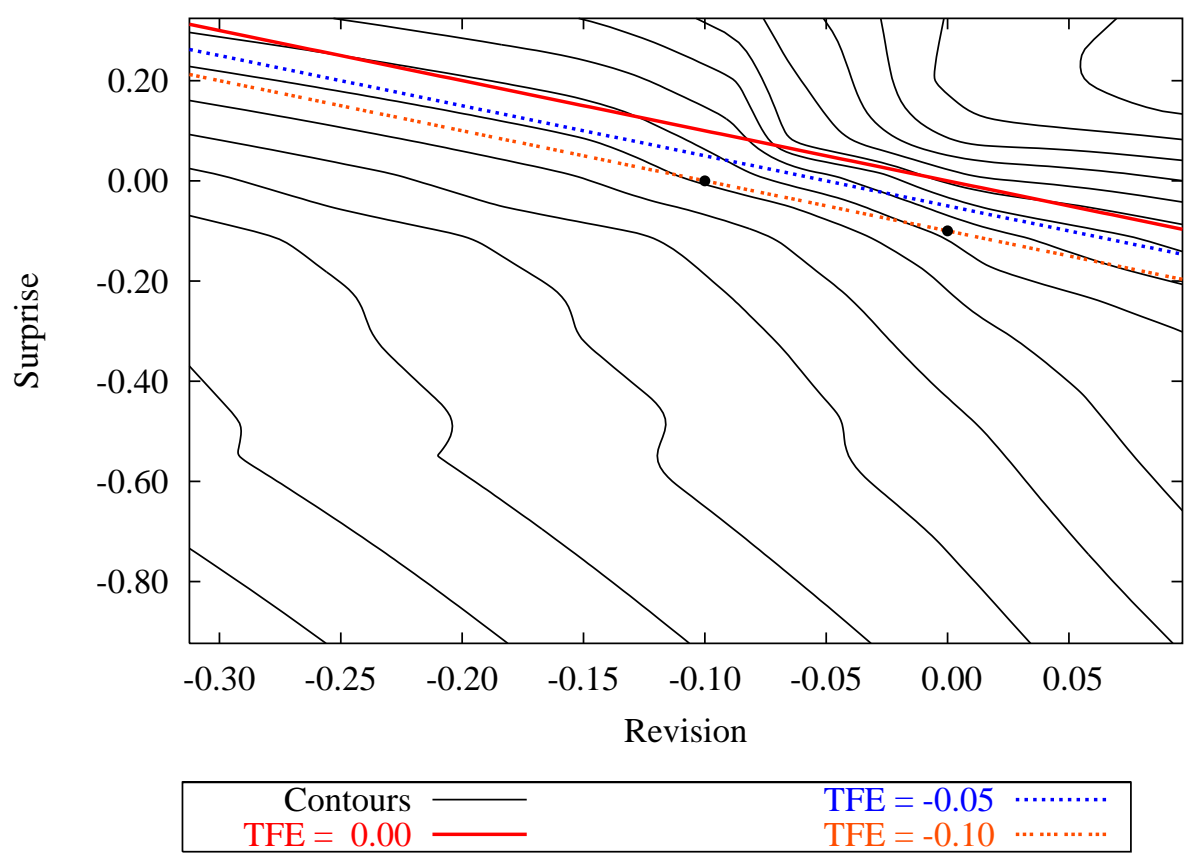


Figure 8: Iso-Return Contours for 1996-2001 Period, 6-Week Revision, |EPS| Scaling Factor The figure displays iso-return contours and three information policy lines. The fit is based on early-period data and the $\mid$ EPS $\mid$ scaling factor, and the revision is measured over a 12 week interval. The sample size is 51,396 firm-quarter observations and the optimal smoothing parameter is 0.15623 , determined by generalized cross-validation. The iso-return contours are spaced at one percentage point intervals; moving from a point on one contour to a point on an adjacent contour represents a one percentage point change in abnormal return. The information policy lines are for total forecast errors (TFE) of $0,-5$, and -10 percent. Movement along an information policy line represents an information release policy by the firm in terms of the timing of information release. Points to the northwest on a policy line represent a policy of releasing bad news in the revision period and good news in the surprise period.

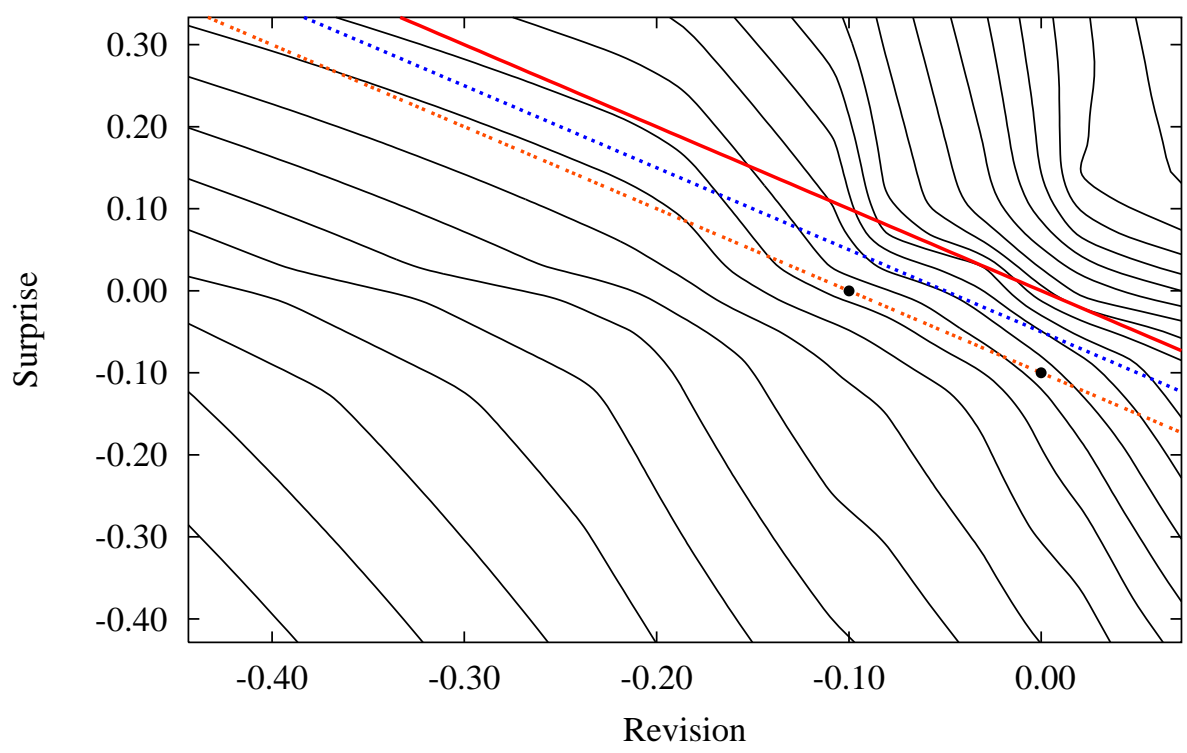

\begin{tabular}{rr}
\hline Contours - & TFE $=-0.05 \quad \cdots \cdots \cdots \cdots$ \\
TFE $=0.00-$ & TFE $=-0.10 \quad \cdots \cdots \cdots \cdots$ \\
\hline
\end{tabular}


Figure 9: Iso-Return Contours for 1987-1995 Period, 6-Week Revision, Price Scaling Factor The figure displays iso-return contours and three information policy lines. The fit is based on early-period data and the price scaling factor, and the revision is measured over a 6 week interval. The sample size is 54,005 firm-quarter observations and the optimal smoothing parameter is 0.10670 , determined by generalized cross-validation. The iso-return contours are spaced at one percentage point intervals; moving from a point on one contour to a point on an adjacent contour represents a one percentage point change in abnormal return. The information policy lines are for total forecast errors (TFE) of $0,-5$, and -10 percent. Movement along an information policy line represents an information release policy by the firm in terms of the timing of information release. Points to the northwest on a policy line represent a policy of releasing bad news in the revision period and good news in the surprise period.

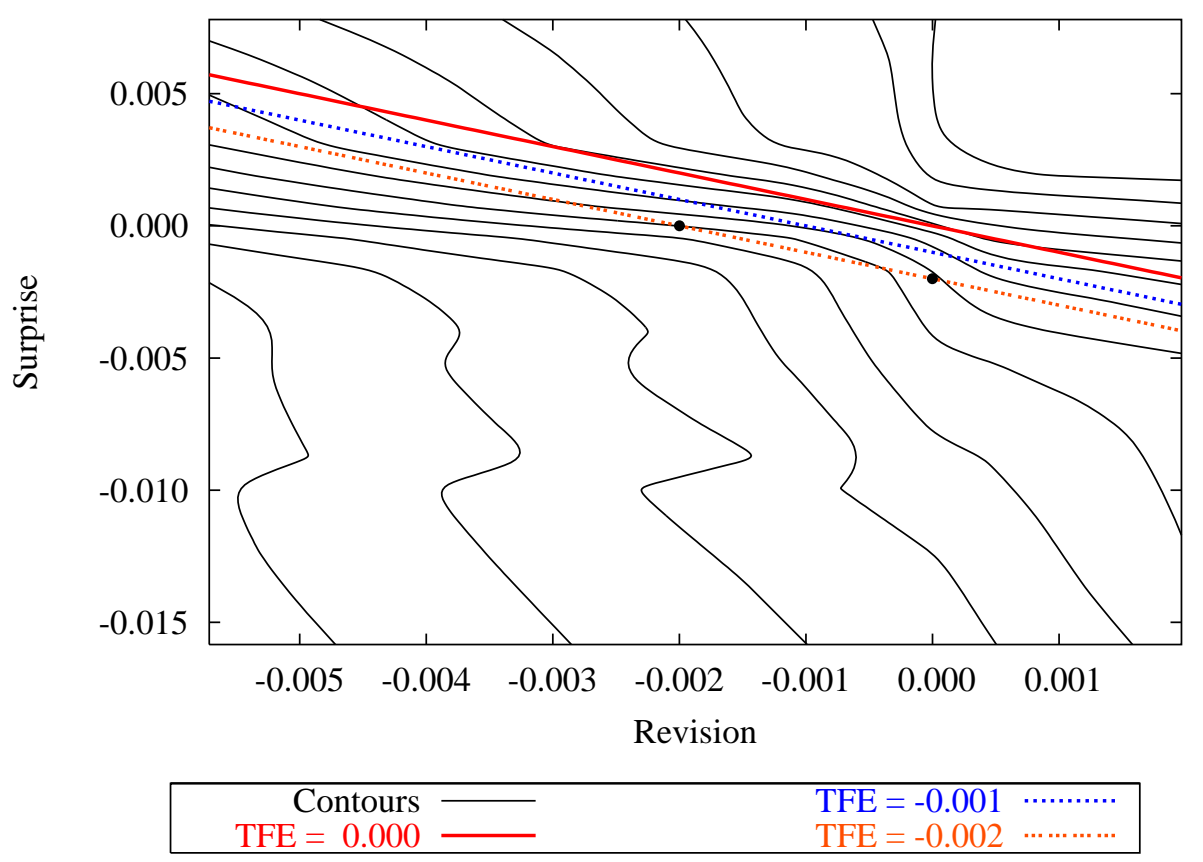


Figure 10: Iso-Return Contours for 1996-2001 Period, 6-Week Revision, Price Scaling Factor The figure displays iso-return contours and three information policy lines. The fit is based on late-period data and the $\mid$ EPS $\mid$ scaling factor, and the revision is measured over a 12 week interval. The sample size is 57,106 firm-quarter observations and the optimal smoothing parameter is 0.15628 , determined by generalized cross-validation. The iso-return contours are spaced at one percentage point intervals; moving from a point on one contour to a point on an adjacent contour represents a one percentage point change in abnormal return. The information policy lines are for total forecast errors (TFE) of $0,-5$, and -10 percent. Movement along an information policy line represents an information release policy by the firm in terms of the timing of information release. Points to the northwest on a policy line represent a policy of releasing bad news in the revision period and good news in the surprise period.

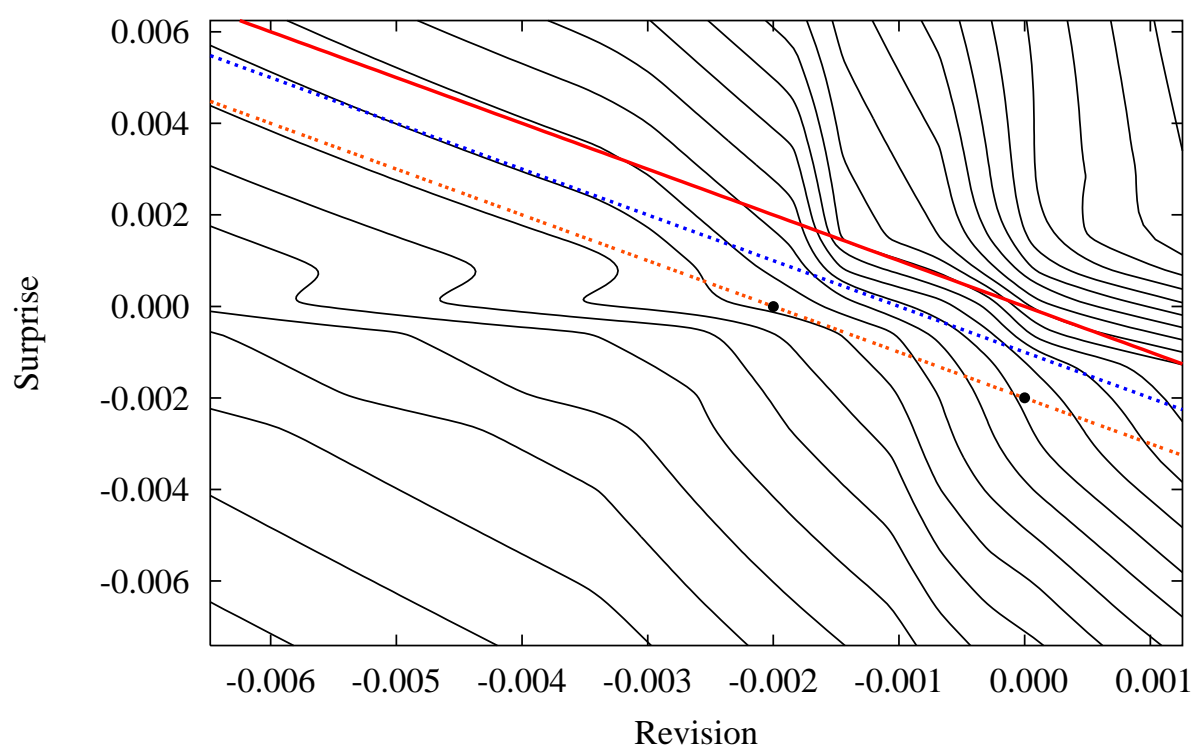

\begin{tabular}{rr} 
Contours $\longrightarrow$ & TFE $=-0.001 \quad \cdots \cdots \cdots$ \\
TFE $=0.000$ & TFE $=-0.002 \quad \ldots \ldots \ldots \ldots$ \\
\hline
\end{tabular}


Figure 11: Fitted Surfaces for 1996-2001 Period, 6-Week Revision, Large and Small, Highand Low-Growth Firms, |EPS| Scaling Factor

The figure displays fitted surfaces for firms split into subsamples based on size and growth prospects, where size is measured by market value and growth prospects by analysts' long-term growth forecasts. A firm is classified as large if its market value is above the median firm market value for the given quarter. A firm is classified as high-growth if its consensus long-term growth forecast is above the sample median consensus long-term growth forecast. The upper two panels display the surfaces for small and large low-growth firms, respectively. The lower two panels display the surfaces for small and large high-growth firms, respectively. The samples sizes and smoothing parameters used for each fit are shown in the appendix.

Small, Low-Growth Firms

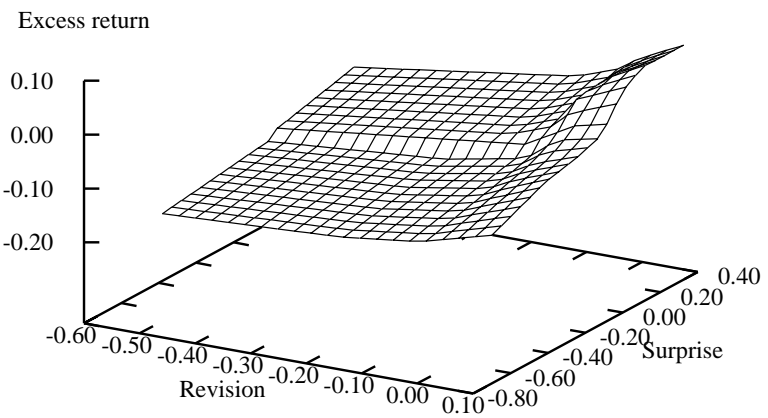

Small, High-Growth Firms

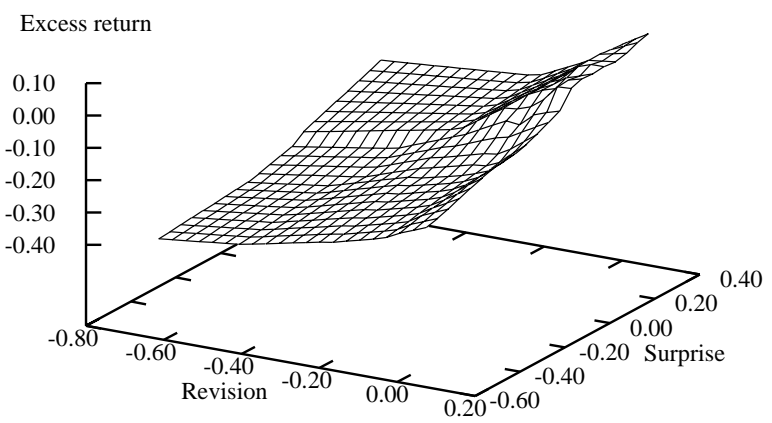

Large, Low-Growth Firms

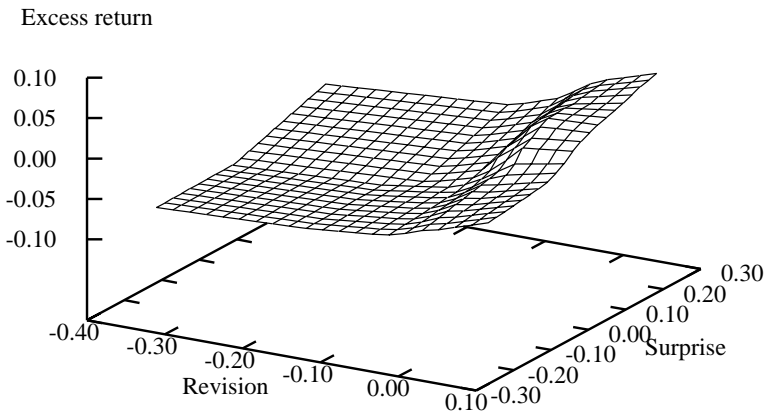

Large, High-Growth Firms

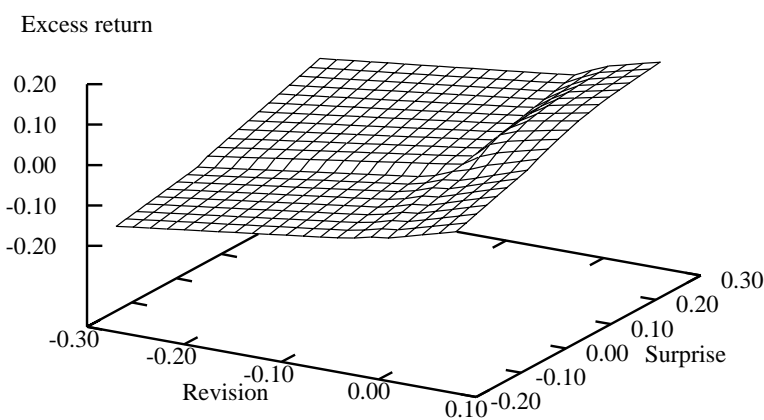


Figure 12: Iso-Return Contours for 1996-2001 Period, 6-Week Revision, Large and Small, High- and Low-Growth Firms, |EPS| Scaling Factor

The figure displays the iso-return contours for the four surfaces shown in figure 11 above. The upper two panels display the contours for small and large low-growth firms, respectively. The lower two panels display the contours for small and large high-growth firms, respectively. Note that the vertical and horizontal axes all vary. The samples sizes and smoothing parameters used for each fit are shown in the appendix. The iso-return contours are spaced at one percentage point intervals; moving from a point on one contour to a point on an adjacent contour represents a one percentage point change in abnormal return. The information policy lines are for total forecast errors (TFE) of $0,-5$, and -10 percent. Movement along an information policy line represents an information release policy by the firm in terms of the timing of information release. Points to the northwest on a policy line represent a policy of releasing bad news in the revision period and good news in the surprise period.
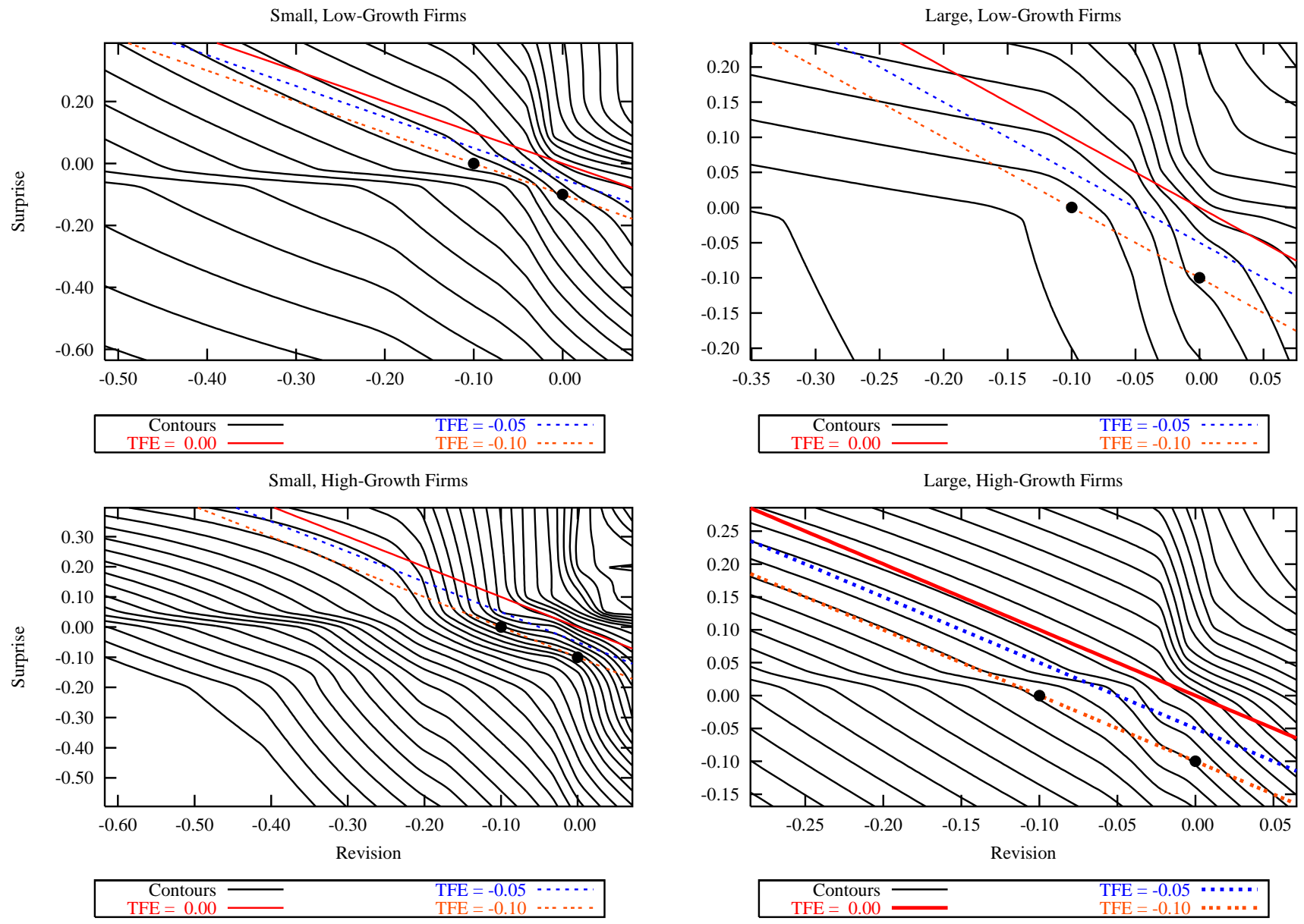
Figure 13: Iso-Return Contours for 1996-2001 Period, 6-Week Revision, Sample Split on Lagged Surprises, |EPS| Scaling Factor

The figure displays the iso-return contours for fits based on late-period data and the $\mid$ EPS $\mid$ scaling factor. The revision is measured over the six week interval. Panel A displays the fit for the subsample of firms with at least 1 lagged negative surprise; Panel B shows the fit for the subsample of all other firms. The sample sizes and smoothing parameters used for each fit are shown in the appendix. The iso-return contours are spaced at one percentage point intervals; moving from a point on one contour to a point on an adjacent contour represents a one percentage point change in abnormal return. The information policy lines are for total forecast errors (TFE) of $0,-5$, and -10 percent. Movement along an information policy line represents an information release policy by the firm in terms of the timing of information release. Points to the northwest on a policy line represent a policy of releasing bad news in the revision period and good news in the surprise period.

Panel A: Firms with at least 1 lagged negative surprise

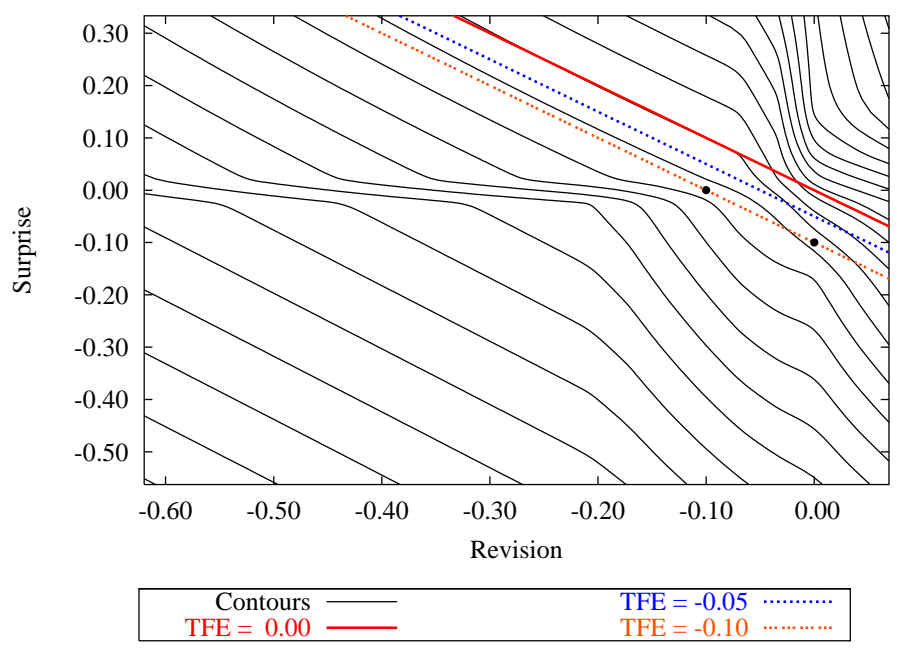

Panel B: All other firms

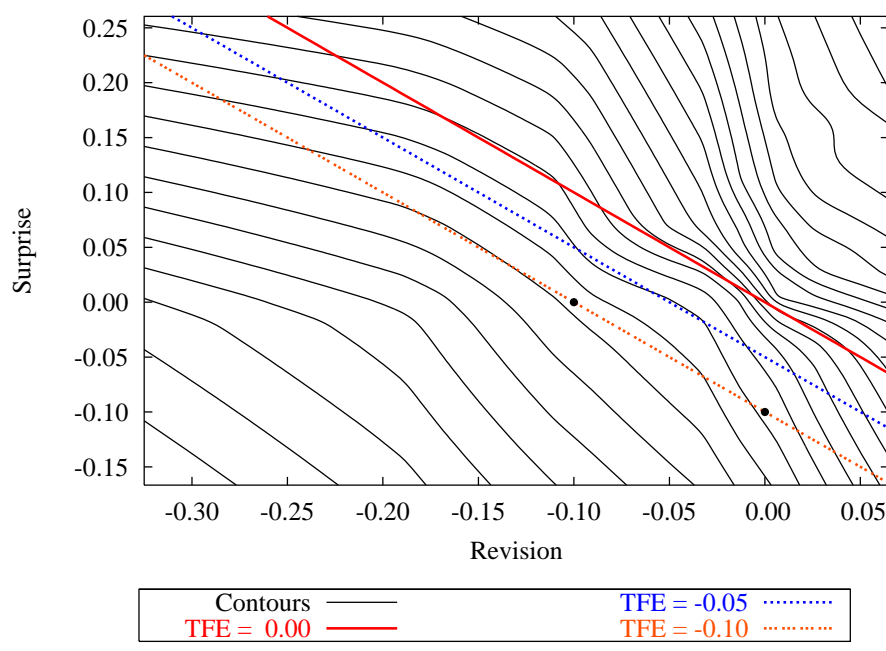




\section{A Smoothing Parameter Selection}

Following Cleveland and Devlin (1988), the expected mean squared error of the loess estimator, given by

$$
M_{h}=\frac{\left[E \sum_{i=1}^{N}\left(\hat{f}_{h}\left(x_{i}\right)-f\left(x_{i}\right)\right)^{2}\right]}{\sigma^{2}},
$$

can be decomposed into a term representing the contribution of bias, $B_{h}$, and the contribution of variance, $V_{h}$, to the overall mean squared error. Here we have subscripted $M$ and $\hat{f}$ by $h$, to emphasize that the calculations are conditional on the degree of smoothing. A larger $h$ is analogous to a wider bandwidth in kernel regression, implying a lower variance estimate at the risk of potentially greater bias. ${ }^{11}$ Denoting the residual sum of squares by $\mathrm{RSS}_{h}$, the estimated error variance by $\hat{\sigma}^{2}$, and by $L_{h}$ the matrix such that $\hat{y}_{h}=L_{h} y$, it can be shown that: ${ }^{12}$

$$
\begin{aligned}
M_{h} & =B_{h}+V_{h}, \text { where } \\
B_{h} & =\frac{\mathrm{RSS}_{h}}{\hat{\sigma}^{2}}-\operatorname{tr}\left[\left(I-L_{h}\right)\left(I-L_{h}\right)^{\prime}\right], \text { and } \\
V_{h} & =\operatorname{tr}\left[L_{h} L_{h}^{\prime}\right],
\end{aligned}
$$

where $I$ is the identity matrix. As shown in Cleveland and Devlin (1988) it is straightforward to compute an estimate $\hat{M}_{h}$ of $M_{h}$. Moreover, it is possible (albeit highly computationally intensive) to compute approximations to the distribution of $\hat{M}_{h}$ under the null hypothesis of zero bias.

The M-plot is a graph of $\hat{M}_{h}$ against $V_{h}$ for a range of values of $h$. The basic idea is to consider a range of smoothing parameters running from the standard OLS fit (including all

\footnotetext{
${ }^{11}$ The term $V_{h}$ is often referred to as the "equivalent number of parameters". This is an intuitive label because, under ordinary least squares, $V_{h}$ is equal to the trace of the projection matrix, which in turn is equal to the number of parameters being estimated. While the loess operator is not a projection matrix, it is nevertheless the case that $V_{h}$ increases as $h$ decreases - less smoothing results in a higher equivalent number of parameters, and vice-versa.

${ }^{12} \mathrm{An}$ estimate of $\sigma^{2}$ is obtained from the residuals of a fit with very small $h$ - a highly localized fit.
} 
of the data in each local regression) to very localized fits in order to see how the contribution of bias changes as the degree of smoothing is varied. Figure A1 presents a representative set of estimates of M-statistics at different degrees of smoothing and their associated confidence intervals under the null hypothesis of zero bias for the late period |EPS|-scaled dataset using the 12 -week revision. ${ }^{13}$ The points on the plot show the estimated M-statistic values. The 45-degree line through the origin and the rightmost M-statistic value show the values of the M-statistics that are expected under the null hypothesis. The vertical lines show the 95 percent confidence bands, while the 'x' symbols on the vertical lines indicate the 90 percent confidence bands. The leftmost point - at an equivalent number of parameters equal to 3 - gives the M-statistic at the OLS fit. It is clear from the plot that the OLS fit is heavily biased - the null hypothesis of zero bias is soundly rejected. As the equivalent number of parameters rises, the estimated M-statistics fall. For an equivalent number of parameters equal between nine and twelve, we cannot reject the null hypothesis of zero bias. As we increase the number of parameters from twelve, the bias again rises, suggesting that the optimal smoothing parameter is the one that uses approximately 60 percent of the data. It should also be noted that this fit is the one that is selected with the generalized crossvalidation procedure for these data.

In order to conserve space, we do not display all of the M-plots for our various subsamples. Table A1 displays the smoothing parameters selected by the generalized cross-validation technique. In general, our M-plot analyses confirmed these settings.

\footnotetext{
${ }^{13}$ These calculations were made on a random sample of 2,500 points from the overall dataset. The calculation of the M-statistics on the full dataset is computationally infeasible.
} 
Figure A1: M-Plot, 12-Week Revision, |EPS| Scaling Factor

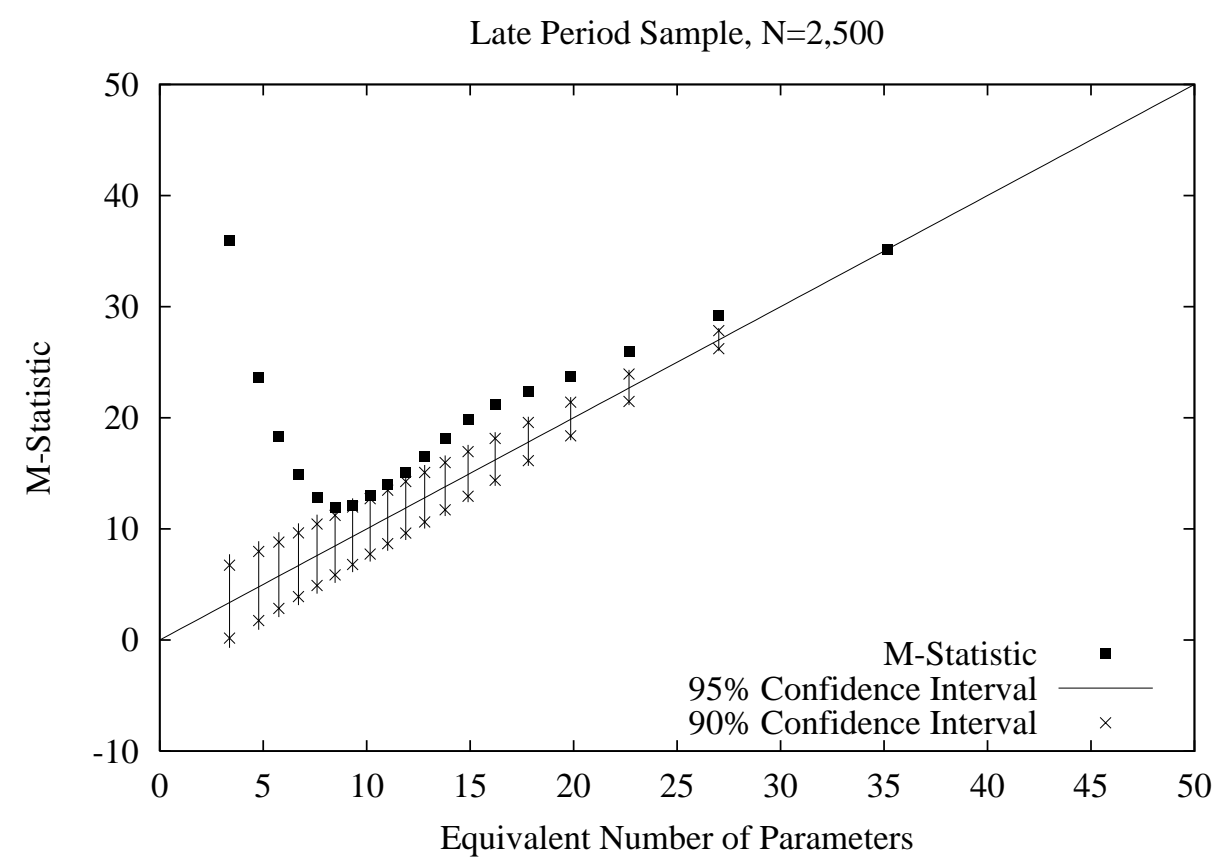


Table A1: Generalized Cross-Validation Results

The table displays the sample size $(\mathrm{N})$, the generalized cross-validation objective function value (GCV), the Akaike Information Criterion (AIC), and the optimal smoothing parameter for all of the estimates discussed in the main text. Panel A displays the main sample splits on sample period, scaling factor, and revision definition. Panel B displays the sample splits on firm growth and size, and Panel C displays the split on recent earnings news.

Panel A: Sample Period, Scaling Factor, and Revision Sample Splits

\begin{tabular}{|c|c|c|c|c|c|c|}
\hline $\begin{array}{l}\text { Sample } \\
\text { period }\end{array}$ & $\begin{array}{l}\text { Scaling } \\
\text { factor }\end{array}$ & $\mathrm{N}$ & Revision & GCV & AIC & $\begin{array}{l}\text { Smoothing } \\
\text { parameter }\end{array}$ \\
\hline \multicolumn{7}{|c|}{ All firms } \\
\hline \multirow[t]{3}{*}{ Early } & |EPS| & 22,987 & $F_{0}-F_{2}$ & $6.248 \mathrm{e}-07$ & -3.24309 & 0.15615 \\
\hline & & 49,041 & $F_{1}-F_{2}$ & $3.063 \mathrm{e}-07$ & -3.19828 & 0.15619 \\
\hline & Price & 54,005 & $F_{1}-F_{2}$ & $2.978 \mathrm{e}-07$ & -3.12987 & 0.10670 \\
\hline \multirow[t]{3}{*}{ Late } & $\mid$ EPS $\mid$ & 42,424 & $F_{0}-F_{2}$ & $9.043 \mathrm{e}-07$ & -2.26050 & 0.62499 \\
\hline & & 51,396 & $F_{1}-F_{2}$ & $7.418 \mathrm{e}-07$ & -2.26679 & 0.15623 \\
\hline & Price & 57,106 & $F_{1}-F_{2}$ & $7.172 \mathrm{e}-07$ & -2.19526 & 0.15628 \\
\hline
\end{tabular}

Panel B: Late Period, $\mid$ EPS $\mid$ Scaling Factor, $F_{1}-F_{2}$ Revision, Growth and Size Sample Splits

\begin{tabular}{llrrrr}
\hline $\begin{array}{l}\text { Growth } \\
\text { Class }\end{array}$ & Size & & & & Smoothing \\
\hline Cow & Small & 15,918 & $2.18 \mathrm{e}-06$ & -2.36219 & 0.22355 \\
Low & Large & 14,968 & $1.08 \mathrm{e}-06$ & -3.12539 & 0.31217 \\
High & Small & 10,460 & $7.34 \mathrm{e}-06$ & -1.56637 & 0.15626 \\
High & Large & 10,079 & $4.81 \mathrm{e}-06$ & -2.02729 & 0.62452 \\
\hline
\end{tabular}

Panel C: Late Period, |EPS| Scaling Factor, $F_{1}-F_{2}$ Revision, Previous Earnings Surprise Sample Split

\begin{tabular}{lrrrr}
\hline & & & & Smoothing \\
Surprise History & $\mathrm{N}$ & GCV & AIC & Parameter \\
\hline No recent negative surprises & 16,709 & $5.464 \mathrm{e}-07$ & -3.34235 & 0.15627 \\
A negative surprise in previous 2 quarters & 15,638 & $1.040 \mathrm{e}-07$ & -3.38635 & 0.61745 \\
\hline
\end{tabular}




\section{References}

Aboody, D. and Kasznik, R.: 2000, CEO stock option awards and the timing of corporate volunatary disclosures, Journal of Accounting and Economics 29, 73-100.

Bartov, E., Givoly, D. and Hayn, C.: 2002, The rewards to meeting or beating earnings expectations, Journal of Accounting Economics 33, 173-204.

Burgstahler, D. and Eames, M. J.: 2002, Management of earnings and analyst forecasts. Working Paper, University of Washington, Seattle, WA.

Chevis, G., Das, S. and Sivaramakrishnan, K.: 2002, Valuation of firms that consistently meet or exceed analysts' earnings forecasts. Working paper.

Cleveland, W. S.: 1979, Robust locally weighted regression and smoothing scatterplots, Journal of the American Statistical Association 74(368), 829-836.

Cleveland, W. S. and Devlin, S. J.: 1988, Locally weighted regression: An approach to regression anaysis by local fitting, Journal of the American Statistical Association 83(403), 596-610.

Cleveland, W. S., Devlin, S. J. and Grosse, E.: 1988, Locally weighted regression: Methods, properties, and computational algorithms, Journal of Econometrics 37(1), 87-114.

Devlin, S. J.: 1986, Locally-weighted multiple regression: Statistical properties and a test for linearity. Unpublished Bell Communications Research Technical Memorandum.

Härdle, W.: 1990, Applied Nonparametric Regression, Cambridge University Press.

Hastie, T. and Loader, C.: 1993, Local regression: Automatic kernel carpentry, Statistical Science 8, 120-143.

Kasznik, R. and Lev, B.: 1995, To warn or not to warn: Management disclosures in the face of an earnings surprise, The Accounting Review pp. 113-134.

Kasznik, R. and McNichols, M. F.: 2002, Does meeting earnings expectations matter? Evidence from analyst forecast revisions and share prices, Journal of Accounting Research 40(3), 727-759.

Kirschner, L. and Bernstein, R.: 2003, 2002 Institutional Factor Survey, Merrill Lynch, New York, NY.

Liu, M. H. and Yao, T.: 2003, The consensus-beating game. Working paper.

Mallows, C. L.: 1973, Some comments on $C_{p}$, Technometrics 15, 661-675.

Matsumoto, D. A.: 2002, Management's incentives to avoid negative earnings surprises, The Accounting Review 77(3), 483-514. 
Nadaraya, E. A.: 1964, On estimating regression, Theory of Probability and Its Applications 9, 141-142.

Richardson, S., Teoh, S. H. and Wysocki, P.: 2003, The walk-down to beatable analyst forecasts: The role of equity issuance and insider trading incentives. Working paper.

Skinner, D. J.: 1994, Why firms voluntarily disclose bad news, Journal of Accounting Research 32(1), 38-60.

Skinner, D. J. and Sloan, R. G.: 1999, Earnings surprises, growth expectations, and stock returns or don't let an earnings torpedo sink your portfolio. Working paper.

Soffer, L. C., Thiagarajan, S. R. and Walther, B. R.: 2000, Earnings preannouncement strategies, Review of Accounting Studies 5, 5-26.

Venkatachalam, M. and Wang, Q.: 2000, The valuation consequences of meeting and beating expectations: Implications of management guidance. Working paper, Stanford University.

Watson, G. S.: 1964, Smooth regression analysis, Sankhya, Series A 26, 359-372. 